\title{
Winner-Take-All and Proportional-Prize Contests: Theory and Experimental Results
}

\author{
Roman M. Sheremeta ${ }^{\mathrm{a}}$, William A. Masters ${ }^{\mathrm{b}}$, and Timothy N. Cason ${ }^{\mathrm{c}}$ \\ ${ }^{a}$ Argyros School of Business and Economics, Chapman University, \\ One University Drive, Orange, CA 92866, U.S.A. \\ ${ }^{\mathrm{b}}$ Department of Food and Nutrition Policy, Tufts University \\ 150 Harrison Avenue, Boston, MA 02111, U.S.A. \\ 'Department of Economics, Krannert School of Management, Purdue University, \\ 403 W. State St., West Lafayette, IN 47906-2056, U.S.A.
}

February 27, 2012

\begin{abstract}
This study provides a unified theoretical and experimental framework in which to compare three canonical types of competition: winner-take-all contests won by the best performer, winner-take-all lotteries where probability of success is proportional to performance, and proportional-prize contests in which rewards are shared in proportion to performance. We introduce random noise to reflect imperfect information, and collect independent measures of risk aversion, other-regarding preferences, and the utility of winning a contest. The main finding is that efforts are consistently higher with winner-take-all contests. The lottery contests have the same Nash equilibrium as proportional prizes, but induce contestants to choose higher efforts and receive lower, more unequal payoffs. This result may explain why contest designers who seek only to elicit effort offer lump-sum prizes, even though contestants would be better off with proportional rewards.
\end{abstract}

JEL Classifications: C72, D72, D74, J33

Keywords: contests, rent-seeking, lotteries, incentives in experiments, risk aversion

Corresponding author: Roman M. Sheremeta; E-mail: sheremet@chapman.edu

For helpful comments we thank Marco Faravelli, Lise Vesterlund, and seminar participants at Purdue University, Universities of Pittsburgh, Hawaii and Monash, as well as participants at the 2010 International Economic Association Conference and the 2010 Southern Economic Association Conference. Any errors are our responsibility. 


\section{Introduction}

A wide variety of competitions arise in economic life, and new ones are regularly introduced to attract effort and reward achievement. Such competitions are commonly modeled as contests, in which agents compete for prize funds by expending costly resources. Although there are many possible contest designs, most theoretical models and most artificially-designed competitions use predetermined and exogenous lump-sum prizes (Konrad, 2009), even when payments could be made proportional to relative performance (Cason et al., 2010). This paper provides a unified theoretical and experimental framework in which to compare contest designs and tests how contestants respond to lump-sum as opposed to proportional incentives.

The simplest contest model in the literature is a winner-take-all competition in which the highest performing contestant wins the prize (Hillman and Riley, 1989). In some versions, such as the rank order tournament of Lazear and Rosen (1981), performance is stochastically related to effort, perhaps due to noise in the observation of effort or in the process by which effort is translated into performance. Even with noise, incentives in such contests follow a step function, offering high-powered incentives for the winner relative to the next-best performer, and then lower incentives for all other contestants. As a result, some contestants may be discouraged from entering (Cason et al., 2010) or from performing well (Brown, 2011) by the presence of a highskill competitor.

A closely-related form of competition is the winner-take-all lottery contest of Tullock (1980), in which the exogenously fixed prize is allocated probabilistically in proportion to observable efforts. This contest format has been most widely used to model naturally-occurring competitions for a lump-sum reward such as political lobbying (Krueger, 1974; Tullock, 1980; Snyder, 1989) or patent races (Fudenberg et al., 1983; Harris and Vickers, 1985, 1987). 
An extensive experimental literature investigates various forms of winner-take-all contests; for a review see Sheremeta et al. (2012). Almost without exception, experimental studies find that contestants incur expenditures that exceed Nash equilibrium levels. Although sometimes desirable (Morgan and Sefton, 2000; Sheremeta, 2010, 2011), over-expenditures typically reduce individual payoffs and decrease economic welfare (Sheremeta and Zhang, 2010; Cason et al., 2011). Moreover, the stark win-or-lose structure of payoffs results in a highly inequitable distribution of economic welfare (Frank and Cook, 1996).

An alternative to winner-take-all competition that might generate more efficient and more equitable outcomes would be to divide the prize in proportion to observable effort (Cason et al., 2010; Schmidt et al., 2011; Eisenkopf and Teyssier, 2012). ${ }^{1}$ In a proportional-prize contest, the fixed prize is shared among contestants according to their performance. The resulting incentives would be similar to a lottery contest, but with lower risks and greater equality of payoffs among contestants. Proportional prizes arise naturally in economic situations such as shared rents (Long and Vousden, 1987), profit sharing and labor productivity (Weitzman and Kruse, 1990), and labor contracts (Zheng and Vikuna, 2007). Contest designers could choose to divide rewards in this way, but typically prefer to make lump-sum awards (McKinsey \& Company, 2009).

This paper offers a unifying model in which the three contest types are special cases of a common theoretical structure. For each case we derive the Nash equilibrium for risk-neutral and self-interested competitors, and implement that contest in a laboratory experiment. A novel feature of the model and the experiment is to vary the random noise that affects the mapping

\footnotetext{
${ }^{1}$ There are only a few experimental studies comparing different contest structures. Davis and Reilly (1998) and Potters et al. (1998) compare behavior in all-pay auctions to lottery contests. Both studies find that, as predicted by theory, perfectly discriminating all-pay auctions generate higher efforts than probabilistic lottery contests, and that in both contests subjects' efforts are higher than Nash equilibrium predictions. However, both of these studies compare only winner-take-all contests and efforts are perfectly observable to the contest designer, so the prize is always allocated to the contestant with the highest effort (an in the all-pay auction). In contrast, our study examines both winner-take-all and proportional-prize contests. Moreover, we introduce noise so that efforts are not perfectly observable. What's observed is only performance, which is a function of noise and effort.
} 
between a contestant's effort and their observed performance. This exogenous noise represents the effect of imperfect information, for contestants who may not know how well their efforts will produce results, and for employers or contest judges who may not be able to observe results directly. We also collect independent measures of subjects' risk aversion, other-regarding preferences, and utility of winning a contest, and use these factors to help understand their choices in the various contests.

Our central finding is that the simple winner-take-all contest generates the highest efforts and consequently the lowest net payoff to participants, which is consistent with the predicted Nash equilibria. The lottery and the proportional-prize contest have the same, lower Nash equilibrium level of effort. Actual competitors in both contests typically over-contribute and hence receive lower payoffs than the Nash equilibrium, but sharing the prize reduces the amount of wasted effort. Sharing the prize also makes effort levels less sensitive to random noise or the subject's measured risk aversion and utility of winning. This direct comparison of the three contest types helps reveal how winner-take-all awards, whether paid deterministically or by lottery, can induce excess contributions and be preferred by contest designers, even though competitors would be better off if prizes were shared proportionally. Contest designers are likely to prefer proportional prizes only if they wish to reduce excess effort, make payoffs more equitable, or make efforts more consistent in the face of variation in noise and contestants' individual preferences.

The rest of the paper is organized as follows: Section 2 presents the theoretical model; Section 3 describes the experimental design, procedures and hypotheses; Section 4 reports the results of the experimental sessions; and Section 5 concludes. 


\section{The Theoretical Model}

Our unified model is a contest in which two risk-neutral players $i$ and $j$ compete for a prize $v$. Both players expend individual efforts $e_{i}$ and $e_{j}$. Every player who exerts effort $e$ has to bear cost $c(e)$, where $c_{e}, c_{e e}>0$. The performance $y_{i}$ of player $i$ is determined by a production function

$$
y_{i}\left(e_{i} \mid \varepsilon_{i}\right)=e_{i} \varepsilon_{i}
$$

where $\varepsilon_{i}$ is a random variable which is drawn from the distribution $F$ on the interval $[0,+\infty)$. This multiplicative production function (1) has been used by O’Keefe et al. (1984), Hirshleifer and Riley (1992), and Gerchak and He (2003). The random component, $\varepsilon_{i}$, can be thought of as production luck, imperfect information about performance, or measurement error. It can also be easily interpreted as an unknown ability $\varepsilon_{i}$ (Rosen, 1986).

The share of the prize received by player $i$ depends on the relative individual performance:

$$
p_{i}\left(e_{i}, e_{j} \mid \varepsilon_{i}, \varepsilon_{j}\right)=y_{i}^{r} /\left(y_{i}^{r}+y_{j}^{r}\right) .
$$

The share of the prize (2) can also be interpreted as the contest success function (CSF), i.e. the probability of winning the contest (Skaperdas, 1996). ${ }^{2}$ Given (1) and (2), the expected payoff for player $i$ can be written as:

$$
E\left(\pi_{i}\right)=p_{i} v-c\left(e_{i}\right)
$$

A deterministic winner-take-all contest similar to the rank-order tournament of Lazear and Rosen (1981) is obtained using the restriction $r=\infty$. A simple all-pay auction of Hillman and Riley (1989) can be obtained by further restriction of the random component, i.e. $\varepsilon_{i}=1$.

\footnotetext{
${ }^{2}$ The production function (1), with multiplicative noise, implies that the CSF (2) satisfies the axioms introduced by Skaperdas (1996). In particular, the CSF satisfies the conditions of a probability distribution: $\sum_{i} p_{i}\left(e_{i}, e_{j} \mid \varepsilon_{i}, \varepsilon_{j}\right)=1$ and $p_{i}\left(e_{i}, e_{j} \mid \varepsilon_{i}, \varepsilon_{j}\right) \geq 0$, for all $e_{i}$ and $e_{j}$. Multiplicative noise also guarantees that the contest success function is homogeneous, i.e., $p_{i}\left(\lambda e_{i}, \lambda e_{j} \mid \varepsilon_{i}, \varepsilon_{j}\right)=p_{i}\left(e_{i}, e_{j} \mid \varepsilon_{i}, \varepsilon_{j}\right)$ for all $\lambda>0$.
} 
Given the noise distribution $F$ and the restriction $r=\infty$, the share of the prize (2) for player $i$ can be written as $p_{i}\left(e_{i}, e_{j} \mid \varepsilon_{i}, \varepsilon_{j}\right)=\operatorname{Pr}\left(e_{i} \varepsilon_{i}>e_{j} \varepsilon_{j}\right)=\operatorname{Pr}\left(\varepsilon_{j}<e_{i} \varepsilon_{i} / e_{j}\right)=\int F\left(\frac{e_{i}}{e_{j}} \varepsilon\right) f(\varepsilon) d \varepsilon$. Taking first order conditions and assuming a symmetric equilibrium, the pure strategy equilibrium effort in the deterministic winner-take-all contest can be obtained from

$$
v \int \varepsilon[f(\varepsilon)]^{2} d \varepsilon=c_{e}(e) e .
$$

Both a probabilistic winner-take-all and a proportional-prize contest arise with the alternative restriction $r=1$. These contests resemble the rent-seeking contest of Tullock (1980), with the difference that performance is subject to random noise $\varepsilon_{i}{ }^{3}$ The difference between the probabilistic and proportional-prize contests is in the interpretation of $p_{i}$. Specifically, in the probabilistic contest, $p_{i}$ represents the probability of winning the prize, while in the proportionalprize contest it represents the share of the prize. The pure strategy symmetric equilibrium in these contests can be obtained from the first order condition, rearranged as

$$
v \iint \frac{\varepsilon_{i} \varepsilon_{j}}{\left(\varepsilon_{i}+\varepsilon_{j}\right)^{2}} f\left(\varepsilon_{i}\right) f\left(\varepsilon_{j}\right) d \varepsilon_{i} d \varepsilon_{j}=c_{e}(e) e .
$$

Closed form solutions for (4) and (5) require assumptions about the distribution of $\varepsilon$ and the cost function $c$. The most commonly used distribution in the contest literature is uniform and the most commonly used cost function is quadratic (Bull et al., 1987; Harbring and Irlenbusch, 2003; Eriksson et al., 2009). Therefore, we assume that $\varepsilon_{i}$ and $\varepsilon_{j}$ are i.i.d. and uniformly distributed on the interval $[1-a, 1+a]$, where $a \in[0,1]$ scales the variance of the distribution. ${ }^{4}$

\footnotetext{
${ }^{3}$ In Tullock (1980), the share of the prize is interpreted as the probability of winning (or CSF) and the production function does not have a random component. The proportional-prize contest with random noise combines features of both Tullock (1980) and Lazear and Rosen (1981). When modeling a conventional Tullock competition with risk neutral agents, adding a noise component into a production function would be redundant since the winner of such a contest is already chosen probabilistically (Fullerton and McAfee, 1999).

${ }^{4}$ The assumption that the error term is uniformly distributed permits a closed form solution for the equilibrium effort. The main conclusions of the model are also robust to other noise distributions, such as a (truncated) normal distribution, a U-shaped quadratic distribution, and the exponential distribution. The numerical simulations are available upon request.
} 
Note that the mean of this distribution is 1 as opposed to the mean of 0 when the noise is additive (Gerchak and He, 2003). We also assume that $c(e)=e^{2} / b$. Given these restrictions, the equilibrium effort in the deterministic winner-take-all contest (4) is given by:

$$
e^{*}=\left(b v \frac{1}{4 a}\right)^{1 / 2}
$$

The equilibrium effort in the probabilistic and proportional-prize contest (5) has a more complicated expression:

$$
e^{*}=\left(b v \frac{-2 a^{2}+a(a-2) \log (1-a)+a(a+2) \log (1+a)+\log \left(1-a^{2}\right)}{8 a^{2}}\right)^{1 / 2} .
$$

The equilibrium efforts in (6) and (7) depend on the value of the prize $v$, the cost parameter $b$, and the variance of the noise $a$. Comparative statics show that an increase in the size of the prize increases individual effort. ${ }^{5}$ It is also straightforward to show that $\partial e^{*} / \partial a<0$ in both (6) and (7), which means that as the level of noise increases the equilibrium effort decreases. ${ }^{6}$ Finally, equilibrium effort in the deterministic contest (6) is higher than in the probabilistic and proportional-prize contest (7) for all values of noise variance $a$.

The expected payoff at the equilibrium (6) is:

$$
E\left(\pi^{*}\right)=\frac{v}{2}\left(1-\frac{1}{2 a}\right)
$$

The expected payoff at the equilibrium (7) is:

$$
E\left(\pi^{*}\right)=\frac{v}{2}\left(1-\frac{-2 a^{2}+a(a-2) \log (1-a)+a(a+2) \log (1+a)+\log \left(1-a^{2}\right)}{4 a^{2}}\right) .
$$

\footnotetext{
${ }^{5}$ Dasgupta and Nti (1998) and Amegashie (2006) also obtain similar results, but in their models the noise enters the contest success function as a constant term instead of a random variable.

${ }^{6}$ One can also evaluate (6) and (7) at the limit as $a \rightarrow 0$. In such a case the deterministic contest transforms into an all-pay auction (Hirshleifer and Riley, 1992) and the probabilistic and proportional-prize contests transform into a rent-seeking contest (Tullock, 1980). We can solve for equilibrium as the variance of noise approaches to zero, by evaluating $e^{*}$ at the limit as $a \rightarrow 0$ : With L'Hopital's rule we can show that $x^{*} \rightarrow V / 4$ as $a \rightarrow 0$. Therefore, as the variance of noise approaches zero, the equilibrium of this proportional-prize contest approaches the equilibrium of a simple Tullock lottery contest without noise (4). A smooth transition exists between this type of contest with a random noise and a lottery contest. There is no such transition between a rank-order contest and an all-pay auction (Che and Gale, 2000).
} 
It is straightforward to show that expected payoff in the probabilistic and proportionalprize contest (9) is higher than the expected payoff in the deterministic winner-take-all contest (8) for all values of noise variance $a .^{7}$

\section{Experimental Design, Hypotheses and Procedures}

Our experimental design is summarized in Table 1, which shows the parameters faced by contestants, equilibrium efforts and expected profits in each of six contests. In all treatments the value of the prize is $v=100$ experimental francs and the restriction on the cost function is $b=$ 100. Column headings denote the type of competition. In the first treatment (denoted DET-L), subjects participate in the deterministic winner-take-all (DET) contest and face low (L) variance: the production noise $\varepsilon$ has a variance of $a=0.5$ that is uniformly distributed on the interval [0.5, 1.5]. The only difference in the DET-H treatment is that the production noise $\varepsilon$ has a high variance $a=1$ that is uniformly distributed on the interval [0,2]. Identical variances are used in the probabilistic (PROB) lottery-type contest and the corresponding proportional-prize (PP) contests, which are designated as PROB-L, PROB-H, PP-L and PP-H.

The theoretical predictions under the four treatments motivate the following hypotheses:

Hypothesis 1: The effort in all contests decreases in the noise variance (L versus $H$ ), leading to higher payoffs.

Hypothesis 2: Deterministic contests (DET) generate higher efforts than probabilistic (PROB) and proportional-prize (PP) contests, and hence lower payoffs.

Hypothesis 3: Probabilistic and proportional-prize contests (PROB and PP) generate the same efforts, and hence the same payoffs.

\footnotetext{
${ }^{7}$ The expected payoff in (8) is non-negative for any $a \in[0.5,1]$ and in (9) it is non-negative for $a \in(0,1]$. For that reason, in the experiment we set $a \geq 0.5$.
} 
We conducted twelve sessions to observe actual behavior in contests and to test theoretical predictions stated in Hypotheses 1, 2 and 3. The sessions employed a total of 144 subjects drawn from the population of undergraduate students at Purdue University, and were implemented using z-Tree (Fischbacher, 2007). There were 12 subjects in the lab during each session. Each session proceeded in six parts. Subjects were given printouts of the instructions, available in the Appendix, at the beginning of each part and the experimenter read the instructions aloud. The first three parts corresponded to the three treatments as in Table $1 .{ }^{8}$ Each of the three treatments lasted for 20 periods. In each period subjects were randomly and anonymously paired. The pairing was changed randomly every period in order to reduce repeated game incentives, since the equilibrium predictions summarized in Table 1 are for static (oneshot) interactions. Each period, both contestants were given an initial endowment of 100 francs. They could use their endowments to submit an effort between 0 and 100 (including 0.1 decimal points) in order to obtain an additional prize of 100 francs. Subjects were given a cost table which showed the quadratic cost associated with each effort. After both contestants chose their efforts, the computer multiplied them by a "personal random number" corresponding to the production noise to determine their final performance.

The computer then compared the performances of the two individuals in each group. In the DET treatments, the highest performing contestant received the entire prize; in the PROB treatments, the computer chose the winner of the entire prize with probabilities that depended on the fraction of total effort chosen by each contestant; and in the PP treatments, both contestants received a share of 100 francs according to their relative performances;. At the end of each

\footnotetext{
${ }^{8}$ The DET-L, PP-L and PROB-L treatments were used in half of the sessions and DET-H, PP-H and PROB-H treatments were used in the other half of the sessions. The treatments were run in different orders in different sessions, with an equal balance of all six possible orderings.
} 
period, both individuals' efforts, random numbers, final performances, and individual earnings for the period were reported to each subject.

In the fourth part of the experiment, subjects were given an endowment of 100 francs and could expend efforts in a deterministic contest in order to be a winner. The procedure followed closely to the DET treatments. The only difference was that the prize value was 0 francs. Subjects were told that they would be informed whether they won the contest or not. Similar to Sheremeta (2010), we used this procedure to obtain a measure of how important it is for subjects to win when winning is costly but provides no monetary reward.

In the fifth part of the experiment, we elicited subjects' risk preferences using a set of 15 lotteries shown in Table 2. Similar to Holt and Laury (2002), in each lottery, subjects were asked to state whether they prefer a safe or risky option. Parameters were set in such a way that a subject with risk-neutral preferences would select the first seven safe options.

Finally, in the sixth part of the experiment, we elicited subjects' preferences towards inequality, using 4 simple binary choices shown in Table 3. These nonstrategic choices affected the subject's income and the income of another anonymously matched subject. Recent studies have explored how various forms of social preferences can affect behavior in contests (Herrmann and Orzen, 2008; Gill and Stone, 2010; Eisenkopf and Teyssier, 2012). We employed choices between payoff distributions that are similar to those used by Bartling et al. (2009). The first option is always a pair of equal payoffs and the second option is always a pair of unequal payoffs. Although option 2 always results in unequal payoffs to the subject and her counterpart, 
in the first two choices the subject's payoff is greater, and in the last two choices the subject's payoff is lower than that of another paired subject. ${ }^{9}$

At the end of each session, 6 out of 60 periods in parts one, two and three were randomly selected for payment ( 2 out of 20 periods for each of the three treatments). The sum of the earnings for these 6 periods was exchanged at rate of 40 francs $=\$ 1$. Subjects were also paid for the single decision made in part four, 1 out of 15 decisions made in part five, and 1 out of 4 decisions made in part six of the experiment. On average, subjects earned $\$ 24.50$ each, which was paid anonymously and in cash. The experimental sessions lasted for about 90 minutes.

\section{Results}

\subsection{Overview}

Table 4 summarizes the average effort and the average payoff by treatment. In the deterministic contest with low noise variance (DET-L), subjects expend average effort of 62.4, which is lower than the predicted equilibrium effort of $70.7 .{ }^{10}$ However, when the noise is high (DET-H), subjects' average effort is 51.2, which is not statistically different from the equilibrium effort of 50.0. In probabilistic contests (PROB-L and PROB-H), subjects expend average efforts of 51.3 and 46.1, and in proportional-prize contests (PP-L and PP-H), subjects expend efforts of 45.2 and 42.4. These observed effort levels are significantly higher than the equilibrium efforts

\footnotetext{
${ }^{9}$ Subjects choosing option 1 for the first two choices, indicate that they are ahead-averse, i.e. subjects choose not to be paid more than others. Similarly, subjects choosing option 1 for the last two choices, indicate that they are behind-averse, i.e. subjects choose not to be paid less than others consistently.

${ }^{10}$ Observed efforts that are less than equilibrium predictions is a surprising result, since previous studies find significant over-contribution of efforts in deterministic winner-take-all contests (Bull et al., 1987; Eriksson et al., 2009). The major difference of our study is the use of multiplicative noise to adjust individual final performance (Gerchak and He, 2003), whereas all other experimental studies employ additive noise. It is possible that subjects perceive multiplicative noise as more risky and thus they restrain their efforts. It is also possible that subjects make mistakes, in which case their decisions may be biased towards the average of a strategy space, i.e. 50.
} 
of 34.6 and 31.1. ${ }^{11}$ Moreover, Figure 1 demonstrates that the pattern of effort expenditures is fairly stable across periods, although a modest downward trend exists for some of the low noise contests. The findings from the deterministic contests are consistent with the previous studies of the rank-order tournaments, documenting that efforts in rank-order tournament are usually not different from theoretical benchmarks (Bull et al., 1987; Harbring and Irlenbusch, 2003; Eriksson et al., 2009). The findings from probabilistic and proportional-prize contests are consistent with previous results of lottery contest experiments, indicating significant overexpenditures relatively to theoretical benchmarks (Davis and Reilly, 1998; Potters et al., 1998; Sheremeta 2010, 2011; Sheremeta and Zhang, 2010).

Result 1. Efforts are highest in deterministic winner-take-all contests, as predicted by the Nash equilibrium. Efforts are lowest with proportional prizes, which elicit less over-contribution of effort relative to Nash equilibrium than the probabilistic lottery contest.

Although the Nash equilibrium has some predictive power for effort means, it is important to emphasize that effort levels are generally inconsistent with play of a symmetric, pure-strategy equilibrium. Figure 2 displays the distribution of efforts in all treatments, and indicates that efforts are distributed on the entire strategy space from 0 to 100 . The distribution of effort is fairly similar across all contests, with standard deviations ranging between 15.6 and 20.9, depending on the contest (Table 4). A high variance in individual efforts is also observed in other experimental studies (Bull et al., 1987; Eriksson et al., 2009), and it clearly demonstrates

\footnotetext{
${ }^{11}$ To support this conclusion we estimated simple panel regressions for each treatment, where the dependent variable is the effort and the independent variables are a constant and a period trend. The model included a random effects error structure, with the individual subject as the random effect, to account for the multiple decisions made by individual subjects. The standard errors were clustered at the session level. Based on a standard Wald test conducted on model estimates, we conclude that in all probabilistic and proportional-prize contests the average efforts are significantly higher than predicted (p-value $<0.01$ ). In the DET-L treatment the average efforts are lower than predicted ( $\mathrm{p}$-value $<0.01)$ and in the DET-H treatment the average effort is not significantly different than predicted $(\mathrm{p}$-value $=0.61)$.
} 
that subjects do not consistently follow the predictions of the symmetric pure strategy equilibrium.

Result 2. Instead of choosing efforts in a narrow range consistent with a pure strategy equilibrium, subjects’ efforts range across the entire strategy space.

\subsection{The Impact of Increased Noise}

As noted above, a novel feature of this experiment is that noise affecting how effort translates into performance is varied systematically in all three contest formats. An increase in noise can be considered, for example, as a decrease in a supervisor's ability to monitor employees in a promotion or bonus tournament. The theoretical model predicts that individual efforts decrease in the noise variance (Hypothesis 1). The experiment provides some support for this prediction. Average efforts decrease significantly from 62.4 to 51.2 in the deterministic contest and from 51.3 to 46.1 in the probabilistic contest. Although average efforts decrease from 45.2 to 42.4 in the proportional-prize contest with an increase in noise, this difference is only marginally statistically significant (one-tailed p-value=0.08). ${ }^{12}$

Result 3. Efforts in contests decrease as the noise variance increases (support for Hypothesis 1).

\subsection{Comparison of Contest Structures}

Our theoretical model predicts that deterministic contests will generate higher efforts than the other two contests (Hypothesis 2). This prediction is clearly supported by our data for both

${ }^{12}$ Random-effect regressions of effort on the treatment dummy variable and a period trend indicates that the difference is significant when comparing DET-H with DET-L and PROB-H with PROB-L (p-value $<0.01$ and pvalue $=0.02$, respectively). These regressions employ a random effects error structure to account for the multiple decisions made by individual subjects. All regressions had clustered standard errors at the session level and dummies to control for order effects of treatments. 
high and low variance treatments. ${ }^{13}$ Moreover, Figure 1 demonstrates that the differences in efforts between treatments persist through all periods of the experiment.

Result 4. Deterministic contests generate higher efforts than proportional-prize and probabilistic contests (support for Hypothesis 2).

Although theory predicts no difference between efforts expended in probabilistic and proportional-prize contests, the data indicate that subjects choose higher efforts in the probabilistic contest than in the proportional-prize contest. This difference is significant for both high and low variance treatments. ${ }^{14}$ Eisenkopf and Teyssier (2012) observe a similar ranking of efforts in probabilistic and proportional-prize contests in a different environment. They attribute this difference to inequity aversion because inequity is necessarily greater in the winner-take-all structure of the probabilistic contest. We explore the influence of such social preferences in the next subsection, based on our directly-measured preferences over own and other's payoffs.

Result 5. Contrary to theoretical predictions, probabilistic contests generate higher efforts than proportional-prize contests (rejection of Hypothesis 3).

Since effort is costly, higher efforts in pursuit of the given prize reduce the subjects' net payoffs. Table 4 shows that average payoffs are highest in the proportional-prize contest, and these payoffs are significantly greater than in the other two contests (except for the probabilistic, high noise case where the difference is significant at only the 7 -percent level).${ }^{15}$ Payoffs in the proportional-prize contest are also more equitable. Figure 3 displays the distribution of payoffs in

\footnotetext{
${ }^{13}$ Random-effect regressions of effort on the treatment dummy variable and a period trend indicates that the difference is significant when comparing DET-H with PP-H and PROB-H, as well as, DET-L with PP-L and PROB$\mathrm{L}$ (all p-values are less than 0.01). All regressions had clustered standard errors at the session level and dummies to control for order effects of treatments.

${ }^{14}$ Random-effect regressions of effort on the treatment dummy variable and a period trend indicates that the difference is significant when comparing PP-H with PROB-H, as well as, PP-L with PROB-L (all p-values are less than 0.01).

${ }^{15}$ Tests are based on the same type of random-effect regressions as described in the previous footnote.
} 
all treatments. Clearly, inequality in payoffs among contestants is significantly lower in both PP treatments than in the DET and PROB treatments.

Result 6. Proportional-prize contests generate higher and more equitable payoffs than deterministic and probabilistic winner-take-all contests.

In summary, the results of our experiment suggest that deterministic contests generate the highest efforts followed by probabilistic and then by proportional-prize contests. As a result, subjects receive the highest expected payoff in proportional-prize contests followed by probabilistic and then by deterministic contests. Moreover, proportional-prize contests generate the most equitable payoffs.

\subsection{Effort and Preferences}

The final three tasks at the end of each experimental session elicited information about individual preference for winning (Sheremeta, 2010), risk aversion (Holt and Laury, 2002), and other-regarding preferences (Bartling et al., 2009). In this section we explore how these factors are related to individual behavior in the different contests.

Several experimental studies provide evidence that in addition to monetary utility, subjects derive utility from winning itself (Sheremeta, 2010; Price and Sheremeta, 2011). We measured subjects' utility of winning by asking them to submit efforts in a deterministic winnertake-all contest where the prize value is 0 . Table 5 reports the distribution of efforts for the prize of 0 and the corresponding average effort difference from the treatment-specific mean for the three contests. Almost $60 \%$ of subjects submitted positive efforts, suggesting that the majority of subjects have a non-monetary utility of winning. Moreover, Table 5 indicates that subjects who 
exert a high effort in this contest for a prize of 0 also tend to exert higher efforts in the three contests.

Theoretical and experimental research on rent-seeking contests suggests that more risk averse subjects exert lower efforts (Hillman and Katz, 1984; Millner and Pratt, 1991; Sheremeta, 2011; Schmidt et al., 2011). To explore the influence of risk aversion among our subjects, we measured their risk preferences using a variant of the multiple price list for lotteries (similar to Holt and Laury, 2002), shown in Table 2. The vast majority of subjects chose the safe option 1 when the probability of the high payoff in the risky option 2 was small, and then crossed over to option 2 at a single point as the high payoff likelihood increased. Table 6 reports the distribution of the total number of safe options chosen by all subjects in the experiment and the corresponding average effort difference from the treatment-specific mean for the three contests. More than $60 \%$ of subjects choose more than 8 safe options, indicating risk averse preferences. Moreover, it appears from Table 6 that subjects who have risk averse preferences often choose lower efforts on average in the contests, although the pattern seems often mixed, especially for the deterministic contest.

A growing body of research has examined how social preferences impact individual behavior in contests (Grund and Sliwka, 2005; Herrmann and Orzen, 2008; Bartling et al., 2009). For example, Grund and Sliwka (2005) show theoretically that inequity averse agents, who dislike disadvantageous and advantageous inequality of payoffs, exert higher efforts than purely self-interested agents. Balafoutas et al. (2012) show experimentally that spiteful subjects compete more aggressively than others when in a contest, but are less likely to enter contests. Eisenkopf and Teyssier (2012) show theoretically that efforts can be lower in proportional-prize contests with inequity averse contestants because payments are more equitable when the prize is 
split. We measured our subjects' other-regarding preferences using binary choices between equal and unequal payoff distributions (Table 3). The choices are constructed such that subjects choosing option 1 for the first two choices, indicate that they are ahead-averse, i.e. subjects choose not to be paid more than others, while subjects choosing option 1 for the last two choices, indicate that they are behind-averse, i.e. subjects choose not to be paid less than others consistently. Table 7 reports the distribution of choices for all subjects and their corresponding average effort differences in the three contests. Only a minority of subjects can be classified as strongly ahead averse, since only 16 percent of subjects prefer $(\$ 2, \$ 2)$ over $(\$ 3, \$ 1)$. Also, only a minority subjects can be classified as strongly behind averse, since only 15.3 percent of subjects prefer ( $\$ 2, \$ 2)$ over ( $\$ 3, \$ 5)$. There appears to be little systematic correlation between these measures of aheadness aversion and the efforts in the contests, but subjects who are behind-averse do tend to choose higher efforts in all three contests.

We explore the significance of these independently-measured preferences on contest effort choices in a set of multivariate regressions shown in Table 8. To capture heterogeneity across individuals, we use a random effect models with individual subject effects. To account for learning that is potentially stronger in early periods, we use inverse of the period (invper) as the time trend. All regressions in Table 8 also include dummy-variables (not shown) to control for treatment order effects. Since strategic behavior is very different across different contests, specification (1) uses only the data from DET treatments, specification (2) uses the data from PROB treatments, and specification (3) uses the data from PP treatments.

The estimation results indicate that the risk-averse variable, which is a dummy variable equal to one if a subject exhibits risk aversion in their lottery choices, is systematically associated with lower effort choices in all contests. The utility-of-winning variable is the costly 
effort expended to win the prize that has zero monetary value. The coefficient estimate is also significant but is positive, suggesting that winning is a component in a subject's utility and that non-monetary utility of winning is an important factor which may explain why subjects exert higher than equilibrium efforts. This effect is largest and most statistically significant in the probabilistic contest, where overbidding relative to the theoretical prediction is most pronounced. Finally, there seems to be no correlation between our measures of other-regarding preferences (aheadness-averse and behindness-averse) and the subjects' effort choices in the contests. This conclusion is robust to alternative specifications that include all or different subsets of the four individual other-regarding preference responses, and it casts some doubt on recent models that use social preferences as a potential explanation for high effort choices observed in winner-takeall contests.

\section{Conclusion}

This study compares the performance of three contest designs in a unified theoretical and experimental framework. In deterministic winner-take-all contests, a lump-sum prize is allocated to the highest performing contestant. Probabilistic winner-take-all contests allocate that prize by lottery with probabilities weighted by the contestants' share of total performance. A proportional-prize contest divides that same prize among the contestants according to their share of total performance. These canonical types of competition are widely observed in economic life, and could potentially be chosen by contest designers. In practice, however, artificial contests are almost universally designed with lump-sum prizes awarded on a winner-take-all basis, even if the prize is divisible and could be shared among competitors in proportion to effort.

Our model compares these three contest designs that have identical costs and prizes for 
all contestants, and clear Nash equilibrium predictions that can be evaluated directly in the laboratory experiment. The experiment included treatments with varying levels of random noise, to reflect imperfect information available to contestants or observers. We also use independent games to elicit contestants' levels of risk aversion, other-regarding preferences, and utility of winning a contest without monetary value, and then test the degree to which these values help explain subjects' choices.

Equilibrium and observed efforts are consistently highest in the deterministic winnertake-all contest. The predicted equilibrium level of effort is lower and identical for the probabilistic and proportional contests. Relative to the Nash equilibrium, subjects incur excess effort in both of these contest types, but this over-contribution is larger in the winner-take-all lottery than when the prize is shared proportionally to effort. As predicted, noise decreases individual efforts in all contests. We also find that subjects with greater measured utility of winning and lower risk aversion exert more effort, but we find no significant effect for otherregarding preferences in these contests.

Our study contributes to several areas of research. First, we provide a unified theoretical model of different contests and show that deterministic and probabilistic winner-take-all and proportional-prize contests can be derived from the same underling theoretical structure. There has been some effort to identify common links between different contests in the literature (Hirshleifer and Riley, 1992; Baye and Hoppe, 2003; Jia, 2007). Hirshleifer and Riley (1992), for example, show how an R\&D race between two players that is modeled as a rank-order tournament of Lazear and Rosen (1981) is equivalent to a lottery contest of Tullock (1980). Similarly, Baye and Hoppe (2003) identify conditions under which innovation tournaments and patent-race models are strategically equivalent to the lottery contest. In contribution to this 
literature, we show that the three canonical models of Tullock (1980), Lazear and Rosen (1981), and Hillman and Riley (1989) can be obtained from a generalized theoretical structure proposed in this paper.

Our study also contributes to experimental literature on contests, reviewed recently in Sheremeta et al. (2012). One principal motivation here is to help understand the behavior of both contestants and contest designers, in particular to explain why artificial contests almost always offer winner-take-all prizes instead of shared rewards (McKinsey and Company 2009). In our setting, winner-take-all prizes elicit higher efforts, leaving contestants with lower average and more unequal payoffs. This robust difference in behavior is consistent with Nash equilibrium when the prize is paid deterministically, and arises despite an identical Nash equilibrium prediction when the prize is awarded probabilistically. The implication is that, if a contest sponsor were to choose winner-take-all incentives in our setting, it would be to elicit effort at the expense of contestants' welfare; a contest designer concerned with social efficiency or inequality would always offer proportional incentives instead. ${ }^{16}$ Testing for generalizability of this conclusion will require further work in other settings, including laboratory and field experiments with varying costs and payoff structures. We anticipate that such work could further advance understanding of why designers choose particular contest rules, and the resulting welfare implications.

\footnotetext{
${ }^{16}$ Obviously, maximizing total effort and/or individual payoffs are not the only objectives that the contest designer may pursue. Often, the objective of a contest designer is to maximize the highest individual effort (as in R\&D races) or to minimize the total equilibrium effort (as in electoral races). These and other objectives would require different types of contest structures that are beyond the scope of the current study.
} 


\section{References}

Amegashie, J. (2006). A contest success function with a tractable noise parameter. Public Choice, 126, 135-144.

Balafoutas, L., Kerschbamer, R. \& Sutter, M. (2012). Distributional preferences and competitive behavior. Journal of Economic Behavior and Organization, forthcoming.

Bartling, B., Fehr, E., Marechal, M.A., \& Schunk, D. (2009). Egalitarianism and Competitiveness. American Economic Review, 99, 93-98.

Baye, M.R., Hoppe, H.C. (2003). The Strategic Equivalence of Rent-Seeking, Innovation, and Patent-Race Games. Games and Economic Behavior, 44, 217-226.

Brown, J. (2011). Quitters Never Win: The (Adverse) Incentive Effects of Competing with Superstars. Journal of Political Economy, 119, 982-1013.

Bull, C., Schotter, A. \& Weigelt, K., (1987). Tournaments and piece rates: an experimental study. Journal of Political Economy 95, 1-33.

Cason, T. N., Masters, W.A. \& Sheremeta, R.M. (2010). Entry into winner-take-all and proportional-prize contests: An experimental study. Journal of Public Economics, 94, 604611.

Cason, T.N., Sheremeta, R.M., Zhang, J. (2011). Communication and Efficiency in Competitive Coordination Games. Purdue University, Working Paper.

Che, Y.K., \& Gale, I. (2000). Difference-form contests and the robustness of all-pay auctions, Games and Economic Behavior, 30, 22-43.

Dasgupta, A., \& Nti, K.O. (1998). Designing an optimal contest. European Journal of Political Economy, 14, 587-603.

Davis, D. \& Reilly, R. (1998). Do many cooks always spoil the stew? An experimental analysis of rent seeking and the role of a strategic buyer. Public Choice, 95, 89-115.

Eisenkopf, G. \& Teyssier, S. (2012). Horizonal and vertical social preferences in tournaments. University of Konstanz, Working Paper.

Eriksson, T., Teyssier, S. \& Villeval, M.C. (2009). Self-selection and the efficiency of tournaments, Economic Inquiry, 47(3), 530-548.

Fischbacher, U. (2007). z-Tree: Zurich Toolbox for Ready-Made Economic Experiments. Experimental Economics, 10, 171-178.

Frank, R. H. and Cook, P. (1995). The Winner-Take-All Society. Penguin Books, New York, New York.

Fudenberg, D., Gilbert, R., Stiglitz, J., and Tirole, J. (1983). Preemption, leapfrogging and competition in patent races, European Economic Review, 22, 3-31.

Fullerton, R.L. \& McAfee, R.P. (1999). Auctioning Entry into Tournaments. Journal of Political Economy, 107, 573-605.

Gerchak, Y. \& He, Q.M. (2003). When will the range of prizes in tournaments increase in the noise or in the number of players? International Game Theory Review, 5, 151-166.

Gill, D. \& Stone, R. (2010). Fairness and desert in tournaments. Games and Economic Behavior, 69(2), 346-364.

Grund, C., \& Sliwka, D. (2005). Envy and Compassion in Tournaments. Journal of Economics and Management Strategy, 14(1), 187-207.

Harbring, C. \& Irlenbusch, B., (2003). An experimental study on tournament design. Labour Economics, 10, 443-464. 
Harris, C., \& Vickers, J. (1985). Perfect equilibrium in a model of a race. Review of Economic Studies, 52, 193-209.

Harris, C., \& Vickers, J. (1987). Racing with uncertainty. Review of Economic Studies, 54, 1-21.

Herrmann, B., \& Orzen, H. (2008). The appearance of homo rivalis: social preferences and the nature of rent seeking. University of Nottingham, Working Paper.

Hillman, A. \& Riley, J.G., (1989). Politically contestable rents and transfers. Economics and Politics, 1, 17-40.

Hillman, A.L., \& Katz, E. (1984). Risk-Averse Rent Seekers and the Social Cost of Monopoly Power. Economic Journal, 94, 104-110.

Hirshleifer, J. \& Riley, J. G. (1992). The analytics of uncertainty and information. New York: Cambridge University Press.

Holt, C.A. \& Laury, S.K. (2002). Risk Aversion and Incentive Effects. American Economic Review, 92, 1644-1655.

Jia, H. (2008). A stochastic derivation of the ratio form of contest success functions. Public Choice, 135, 125-130.

Konrad, K.A. (2009). Strategy and Dynamics in Contests. New York, NY: Oxford University Press.

Krueger, A.O. (1974). The Political Economy of the Rent-Seeking Society. American Economic Review, 64, 291-303.

Lazear, E.P. \& Rosen, S., (1981). Rank-order tournaments as optimum labor contracts. Journal of Political Economy 89, 841-864.

Long, N.V., and Vousden, N. (1987). Risk-averse rent seeking with shared rents. Economic Journal, 97, 971-985.

McKinsey \& Co. (2009). 'And the winner is...': Capturing the promise of philanthropc prizes. Online at http://mckinseyonsociety.com/capturing-the-promise-of-philanthropic-prizes.

Millner, E.L., \& Pratt, M.D. (1991). Risk Aversion and Rent-Seeking: An Extension and Some Experimental Evidence. Public Choice, 69, 81-92.

Morgan, J., \& Sefton, M. (2000). Funding Public Goods with Lotteries: Experimental Evidence. Review of Economic Studies, 67, 785-810.

O'Keeffe, M.W., Viscusi, K. \& Zeckhauser, I.L., (1984). Economic contests: Comparative reward schemes. Journal of Labor Economics, 2, 27-56.

Potters, J.C., De Vries, C.G. \& Van Linden, F. (1998). An experimental examination of rational rent seeking. European Journal of Political Economy, 14, 783-800.

Price, C.R., \& Sheremeta, R.M. (2011). Endowment Effects in Contests. Economics Letters, 111, 217-219.

Rosen, S. (1986). Prizes and incentives in elimination tournaments. American Economic Review, 76, 701-715.

Schmidt, D., Sheremeta, R.M., Shupp, R., \& Walker, J. (2011). Resource Allocation Contests: Experimental Evidence. Indiana University, Working Paper.

Sheremeta, R.M. (2010). Experimental Comparison of Multi-Stage and One-Stage Contests. Games and Economic Behavior, 68, 731-747.

Sheremeta, R.M. (2011). Contest Design: An Experimental Investigation. Economic Inquiry, 49, 573-590.

Sheremeta, R.M., Dechenaux, E., \& Kovenock, D. (2012). A Survey of Experimental Findings on Contests, All-Pay Auctions and Tournaments. ESI, Working Paper.

Skaperdas, S. (1996). Contest success functions. Economic Theory, 7, 283-290. 
Snyder, J. (1989). Election goals and the allocation of campaign resources. Econometrica, 57, $630-660$.

Tullock, G. (1980). Efficient Rent Seeking. In James M. Buchanan, Robert D. Tollison, Gordon Tullock, (Eds.), Toward a theory of the rent-seeking society. College Station, TX: Texas A\&M University Press, pp. 97-112.

Weitzman M.L., and Kruse, D.L., (1990). Profit Sharing and Productivity, in A. Blinder (ed.) Paying for Productivity, Brookings.

Zheng, X. and T. Vukina (2007). Efficiency gains from organizational innovation: Comparing ordinal and cardinal tournament games in broiler contracts. International Journal of Industrial Organization, 25, 843-859. 
Table 1: Experimental Parameters and Theoretical Predictions

\begin{tabular}{lcccccc}
\hline Treatment & DET-L & DET-H & PROB-L & PROB-H & PP-L & PP-H \\
\hline Value of the Prize, $v$ & 100 & 100 & 100 & 100 & 100 & 100 \\
Noise Parameter, $a$ & 0.5 & 1 & 0.5 & 1 & 0.5 & 1 \\
\hline Equilibrium Effort, $e^{*}$ & 70.7 & 50.0 & 34.6 & 31.1 & 34.6 & 31.1 \\
Expected Payoff, $E\left(\pi^{*}\right)$ & 0.0 & 25.0 & 38.0 & 40.3 & 38.0 & 40.3 \\
\hline
\end{tabular}

Table 2: Lottery Choices for Elicitation of Risk Preferences

\begin{tabular}{cccc}
\hline \hline Choice & $\begin{array}{c}\text { Option } 1 \\
\text { (Safe Option) }\end{array}$ & \multicolumn{2}{c}{$\begin{array}{c}\text { Option } 2 \\
\text { (Risky Option) }\end{array}$} \\
\hline$\# 1$ & $\$ 1$ & $0 / 20$ of $\$ 3$ & $20 / 20$ of $\$ 0$ \\
$\# 2$ & $\$ 1$ & $1 / 20$ of $\$ 3$ & $19 / 20$ of $\$ 0$ \\
$\# 3$ & $\$ 1$ & $2 / 20$ of $\$ 3$ & $18 / 20$ of $\$ 0$ \\
$\# 4$ & $\$ 1$ & $3 / 20$ of $\$ 3$ & $17 / 20$ of $\$ 0$ \\
$\# 5$ & $\$ 1$ & $4 / 20$ of $\$ 3$ & $16 / 20$ of $\$ 0$ \\
$\# 6$ & $\$ 1$ & $5 / 20$ of $\$ 3$ & $15 / 20$ of $\$ 0$ \\
$\# 7$ & $\$ 1$ & $6 / 20$ of $\$ 3$ & $14 / 20$ of $\$ 0$ \\
$\# 8$ & $\$ 1$ & $7 / 20$ of $\$ 3$ & $13 / 20$ of $\$ 0$ \\
$\# 9$ & $\$ 1$ & $8 / 20$ of $\$ 3$ & $12 / 20$ of $\$ 0$ \\
$\# 10$ & $\$ 1$ & $9 / 20$ of $\$ 3$ & $11 / 20$ of $\$ 0$ \\
$\# 11$ & $\$ 1$ & $10 / 20$ of $\$ 3$ & $10 / 20$ of $\$ 0$ \\
$\# 12$ & $\$ 1$ & $11 / 20$ of $\$ 3$ & $9 / 20$ of $\$ 0$ \\
$\# 13$ & $\$ 1$ & $12 / 20$ of $\$ 3$ & $8 / 20$ of $\$ 0$ \\
$\# 14$ & $\$ 1$ & $13 / 20$ of $\$ 3$ & $7 / 20$ of $\$ 0$ \\
$\# 15$ & $\$ 1$ & $14 / 20$ of $\$ 3$ & $6 / 20$ of $\$ 0$ \\
\hline
\end{tabular}

* Subjects choose between a safe option 1 (\$1 with certainty) or a risky option 2 (a chance of receiving either $\$ 3$ or $\$ 0$ ).

Table 3: Dictator Allocations for Elicitation of Other-Regarding Preferences

\begin{tabular}{ccc}
\hline \hline Choice & $\begin{array}{c}\text { Option 1 } \\
\text { (Self, Other) }\end{array}$ & $\begin{array}{c}\text { Option 2 } \\
\text { (Self, Other) }\end{array}$ \\
\hline$\# 1$ & $\$ 2, \$ 2$ & $\$ 2, \$ 1$ \\
$\# 2$ & $\$ 2, \$ 2$ & $\$ 3, \$ 1$ \\
$\# 3$ & $\$ 2, \$ 2$ & $\$ 2, \$ 4$ \\
$\# 4$ & $\$ 2, \$ 2$ & $\$ 3, \$ 5$ \\
\hline
\end{tabular}

* Subjects choose between option 1 (equal payoffs) or option 2 (unequal payoffs). 
Table 4: Average Efforts and Payoffs

\begin{tabular}{lcccccc}
\hline \hline Treatment & DET-L & DET-H & PROB-L & PROB-H & PP-L & PP-H \\
\hline Equilibrium & 70.7 & 50.0 & 34.6 & 31.1 & 34.6 & 31.1 \\
\cline { 2 - 7 } Average & 62.4 & 51.2 & 51.3 & 46.1 & 45.2 & 42.4 \\
Median & 65.0 & 50.0 & 51.0 & 47.0 & 45.0 & 41.3 \\
St. Dev. & 20.9 & 17.4 & 20.0 & 17.2 & 15.6 & 17.8 \\
\hline \multicolumn{7}{c}{ Payoff } \\
\hline Equilibrium & 0.0 & 25.0 & 38.0 & 40.3 & 38.0 & 40.3 \\
\cline { 2 - 7 } Average & 6.7 & 20.8 & 19.7 & 25.8 & 27.1 & 28.9 \\
Median & 0 & 0 & 0 & 0 & 27.6 & 28.4 \\
St. Dev. & 47.1 & 49.0 & 49.7 & 49.5 & 16.5 & 27.2 \\
\hline
\end{tabular}

Table 5: Elicited Utility of Winning and Efforts

\begin{tabular}{ccccc}
\hline \hline $\begin{array}{c}\text { Effort in a } \\
\text { Tournament with } \\
\text { the Prize of 0 }\end{array}$ & $\begin{array}{c}\text { Percent of } \\
\text { Subjects }\end{array}$ & $\begin{array}{c}\text { Mean Effort } \\
\text { Deviation in } \\
\text { DET } \\
\text { treatments }\end{array}$ & $\begin{array}{c}\text { Mean Effort } \\
\text { Deviation in } \\
\text { PROB } \\
\text { treatments }\end{array}$ & $\begin{array}{c}\text { Mean Effort } \\
\text { Deviation in } \\
\text { PP } \\
\text { treatments }\end{array}$ \\
\hline 0 & $42.4 \%$ & -1.13 & -3.70 & -0.88 \\
$0.1-10$ & $22.9 \%$ & 0.59 & 1.10 & -0.71 \\
$10.1-20$ & $2.1 \%$ & 3.29 & 10.73 & 3.43 \\
$20.1-30$ & $4.2 \%$ & -5.90 & 0.82 & -4.77 \\
$30.1-40$ & $5.6 \%$ & -5.65 & -3.77 & -6.50 \\
$40.1-50$ & $8.3 \%$ & 2.78 & 1.15 & 1.83 \\
$50.1-60$ & $4.2 \%$ & -0.44 & 8.95 & 1.03 \\
$60.1-70$ & $6.3 \%$ & 0.88 & 6.94 & 6.30 \\
$70.1-100$ & $4.2 \%$ & 13.45 & 9.32 & 10.10 \\
\hline
\end{tabular}

* Effort deviations are effort choices minus treatment-specific mean efforts

Table 6: Elicited Risk Preferences and Efforts

\begin{tabular}{ccccc}
\hline \hline $\begin{array}{c}\text { Total } \\
\text { Number of } \\
\text { Safe Choices }\end{array}$ & $\begin{array}{c}\text { Percent of } \\
\text { Subjects }\end{array}$ & $\begin{array}{c}\text { Mean Effort } \\
\text { Deviation in } \\
\text { DET } \\
\text { treatments }\end{array}$ & $\begin{array}{c}\text { Mean Effort } \\
\text { Deviation in } \\
\text { PROB } \\
\text { treatments }\end{array}$ & $\begin{array}{c}\text { Mean Effort } \\
\text { Deviation in } \\
\text { PP } \\
\text { treatments }\end{array}$ \\
\hline $0-4$ & $1.4 \%$ & -3.25 & 1.85 & -6.05 \\
$5-6$ & $11.8 \%$ & 2.36 & 2.73 & 3.81 \\
$7-8$ & $23.6 \%$ & 3.90 & 4.27 & 1.67 \\
$9-10$ & $36.1 \%$ & -1.43 & 0.23 & -1.08 \\
$11-12$ & $18.8 \%$ & -4.35 & -5.41 & -1.40 \\
$13-15$ & $8.3 \%$ & 2.07 & -4.83 & -1.49 \\
\hline
\end{tabular}

* Effort deviations are effort choices minus treatment-specific mean efforts. 
Table 7: Elicited Other-Regarding Preferences and Efforts

\begin{tabular}{ccccc}
\hline \hline $\begin{array}{c}\text { Choice } \\
\text { (Self, Other) }\end{array}$ & $\begin{array}{c}\text { Percent of } \\
\text { Subjects }\end{array}$ & $\begin{array}{c}\text { Mean Effort } \\
\text { Deviation in DET } \\
\text { treatments }\end{array}$ & $\begin{array}{c}\text { Mean Effort } \\
\text { Deviaion in } \\
\text { PROB } \\
\text { treatments }\end{array}$ & $\begin{array}{c}\text { Mean Effort } \\
\text { Deviation in } \\
\text { PP } \\
\text { treatments }\end{array}$ \\
\hline$\$ 2, \$ 2$ & $84.7 \%$ & -0.03 & 0.66 & 0.42 \\
$\$ 2, \$ 1$ & $15.3 \%$ & 0.13 & -3.52 & -2.45 \\
\hline$\$ 2, \$ 2$ & $16.0 \%$ & -3.21 & 0.29 & 1.30 \\
$\$ 3, \$ 1$ & $84.0 \%$ & 0.60 & -0.03 & -0.26 \\
\hline$\$ 2, \$ 2$ & $41.7 \%$ & 2.32 & 3.57 & 0.42 \\
$\$ 2, \$ 4$ & $58.3 \%$ & -1.67 & -2.51 & -0.33 \\
\hline$\$ 2, \$ 2$ & $15.3 \%$ & 1.83 & 2.21 & 0.37 \\
$\$ 3, \$ 5$ & $84.7 \%$ & -0.34 & -0.37 & -0.08 \\
\hline
\end{tabular}

* Effort deviations are effort choices minus treatment-specific mean efforts.

Table 8: Random-Effect Regression Models of Effort

\begin{tabular}{lccc}
\hline \hline Treatment & DET & PROB & PP \\
\hline Dependent variable, effort & $(1)$ & $(2)$ & $(3)$ \\
\hline noise-variance & $-10.27^{* * *}$ & $-3.80^{*}$ & -2.00 \\
[treatment dummy] & $(3.24)$ & $(2.04)$ & $(2.22)$ \\
utility-of-winning & $0.07^{*}$ & $0.13^{* * *}$ & $0.07^{*}$ \\
[effort for prize value 0] & $(0.04)$ & $(0.04)$ & $(0.04)$ \\
risk-averse & $-3.69^{* *}$ & $-5.67 * * *$ & $-3.24^{*}$ \\
[1 if number of safe options $1>8]$ & $(1.61)$ & $(1.89)$ & $(1.84)$ \\
aheadness-averse & -4.08 & 0.91 & 1.59 \\
[1 if $(2,2)$ is preferred to $(2,1)$ and $(3.1)]$ & $(3.09)$ & $(2.71)$ & $(2.97)$ \\
behindness-averse & 0.09 & -0.93 & -1.60 \\
[1 if $(2,2)$ is preferred to $(2,4)$ and $(3,5)]$ & $(3.15)$ & $(2.09)$ & $(2.16)$ \\
invper & $-6.57^{* * *}$ & 1.26 & 1.53 \\
[inverse of a period trend, $1 / t]$ & $(2.20)$ & $(3.31)$ & $(3.15)$ \\
constant & $64.65^{* * *}$ & $52.92^{* * *}$ & $43.60^{* * *}$ \\
& $(2.52)$ & $(2.44)$ & $(2.48)$ \\
\hline Observations & 2880 & 2880 & 2880 \\
Number of subjects & 144 & 144 & 144 \\
\hline
\end{tabular}

* significant at $10 \%,{ }^{* *}$ significant at $5 \%, * * *$ significant at $1 \%$.

Standard errors in parenthesis. 


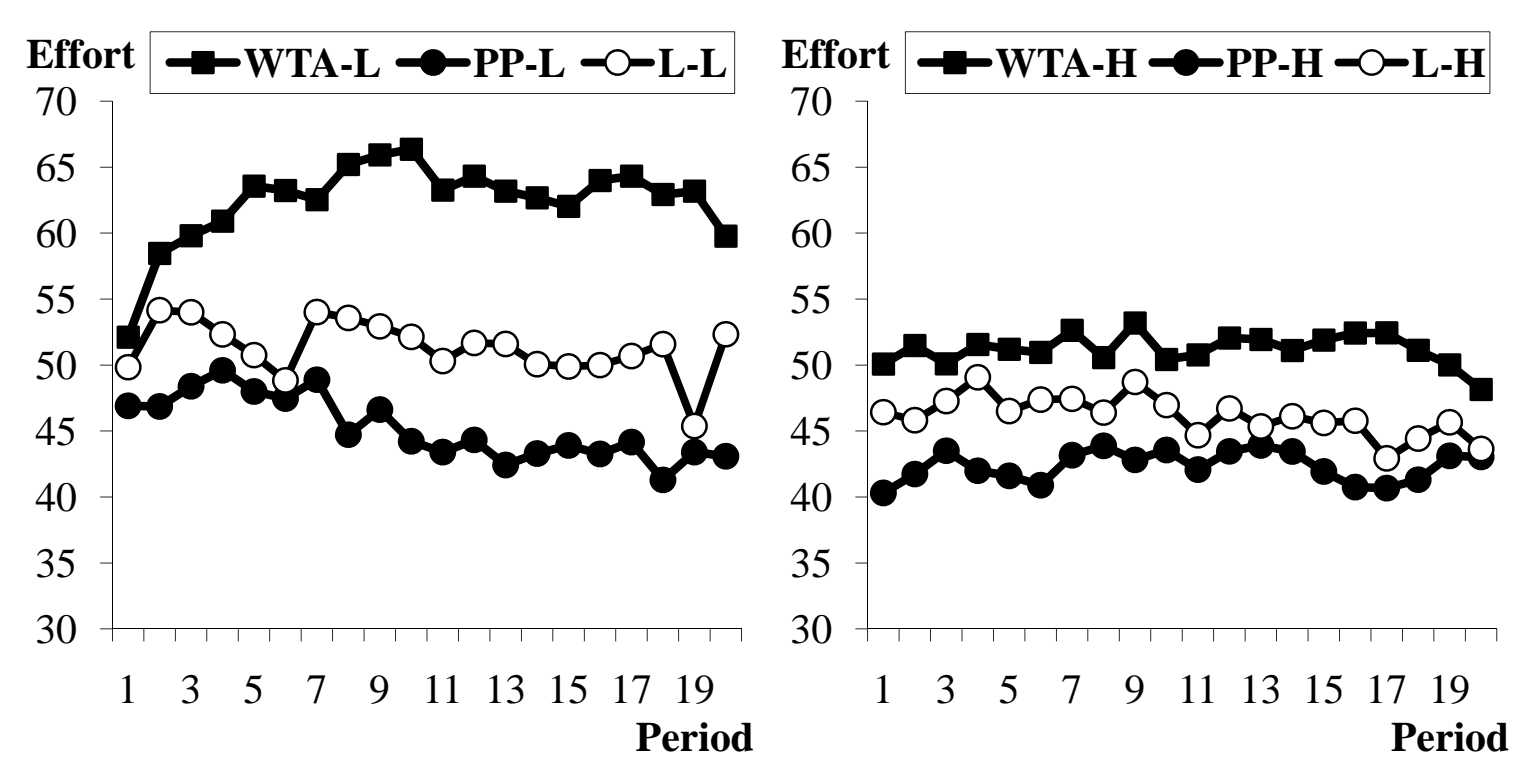

Figure 1: Average Effort over Periods
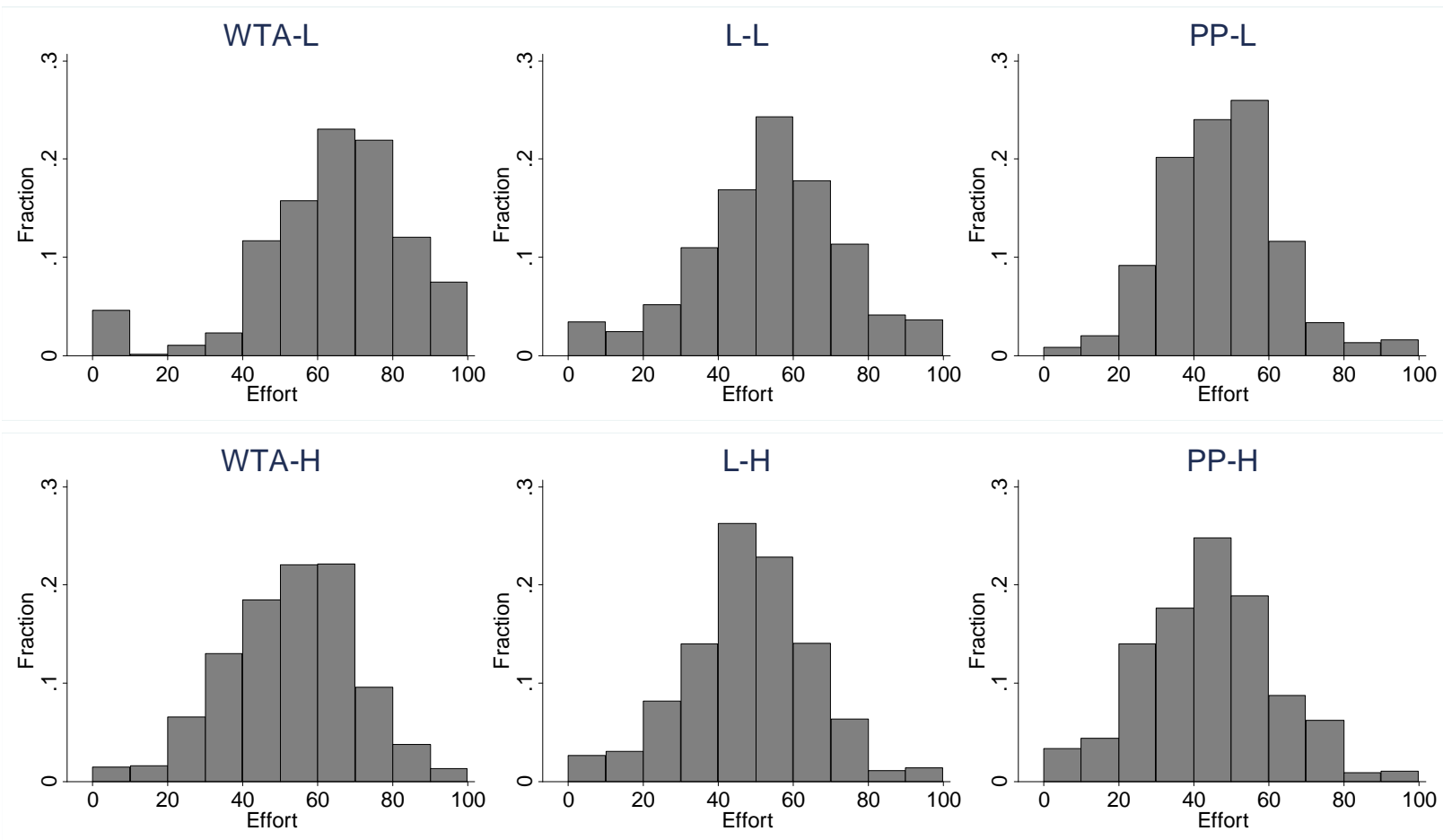

Figure 2: Distribution of Efforts 

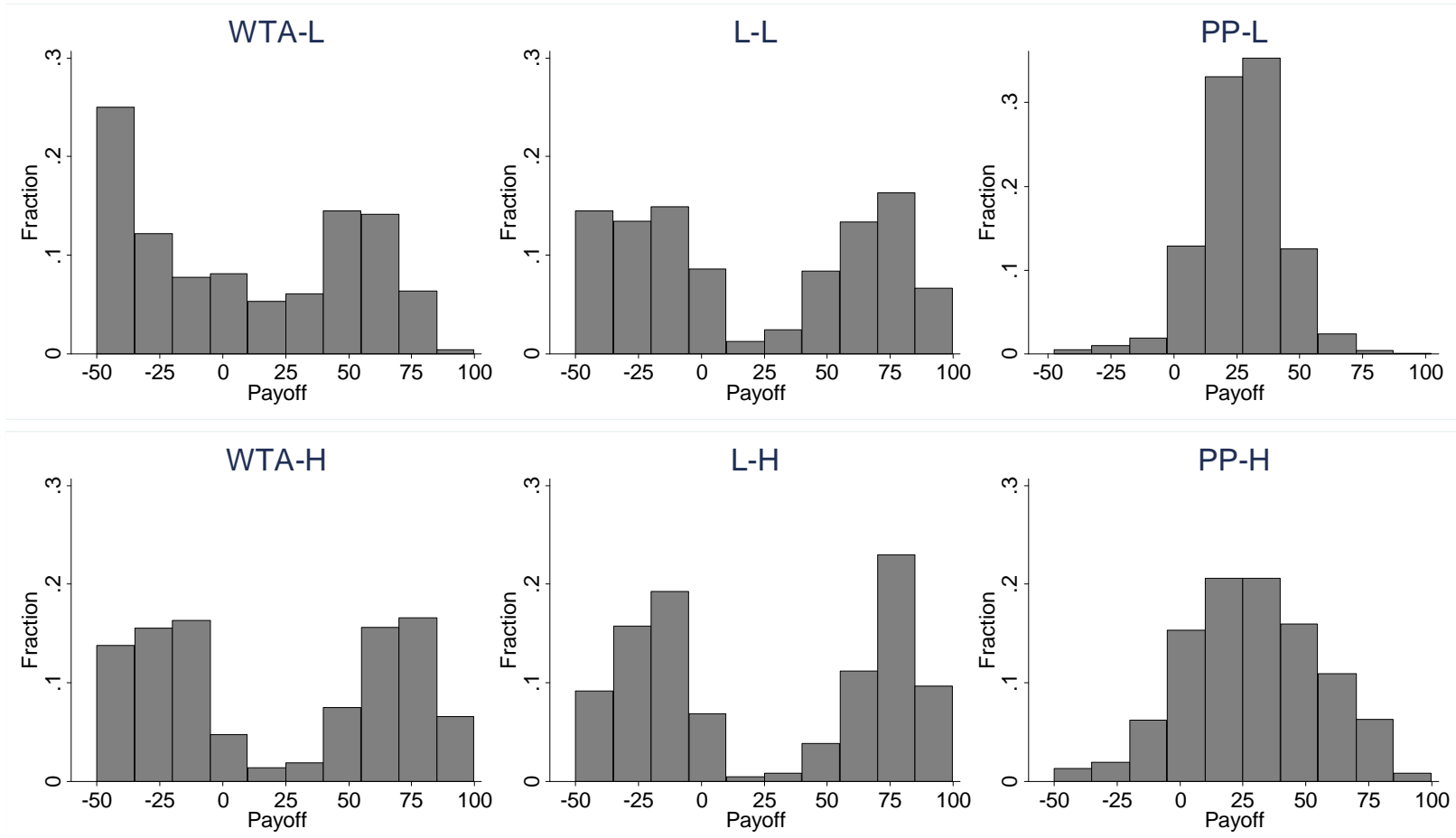

Figure 3: Distribution of Payoffs 


\section{Appendix}

\section{GENERAL INSTRUCTIONS}

This is an experiment in the economics of strategic decision making. Various research agencies have provided funds for this research. The instructions are simple. If you follow them closely and make appropriate decisions, you can earn an appreciable amount of money.

The experiment will proceed in six parts. Each part contains decision problems that require you to make a series of economic choices which determine your total earnings. The currency used in Parts 1 through 4 of the experiment is francs. Francs will be converted to U.S. dollars at a rate of $\mathbf{6 0}$ francs to $\mathbf{1}$ dollar. The currency used in Parts 5 and 6 of the experiment is U.S. dollars. At the end of today's experiment, you will be paid in private and in cash. There are $\mathbf{1 2}$ participants in today's experiment.

It is very important that you remain silent and do not look at other people's work. If you have any questions, or need assistance of any kind, please raise your hand and an experimenter will come to you. If you talk, laugh, exclaim out loud, etc., you will be asked to leave and you will not be paid. We expect and appreciate your cooperation.

\section{INSTRUCTIONS FOR PART 1 \\ YOUR DECISION}

This part of the experiment consists of $\mathbf{2 0}$ decision-making periods. At the beginning of each period, you will be randomly and anonymously paired with someone else in a group of two participants. The composition of your group will be changed randomly every period. Each period, both participants will be given an initial endowment of 100 francs. You will use this endowment to bid for a share of an additional 100 francs reward available in each period. You may bid any number between $\mathbf{0}$ and $\mathbf{1 0 0}$ (including 0.1 decimal points). An example of your decision screen is shown below.

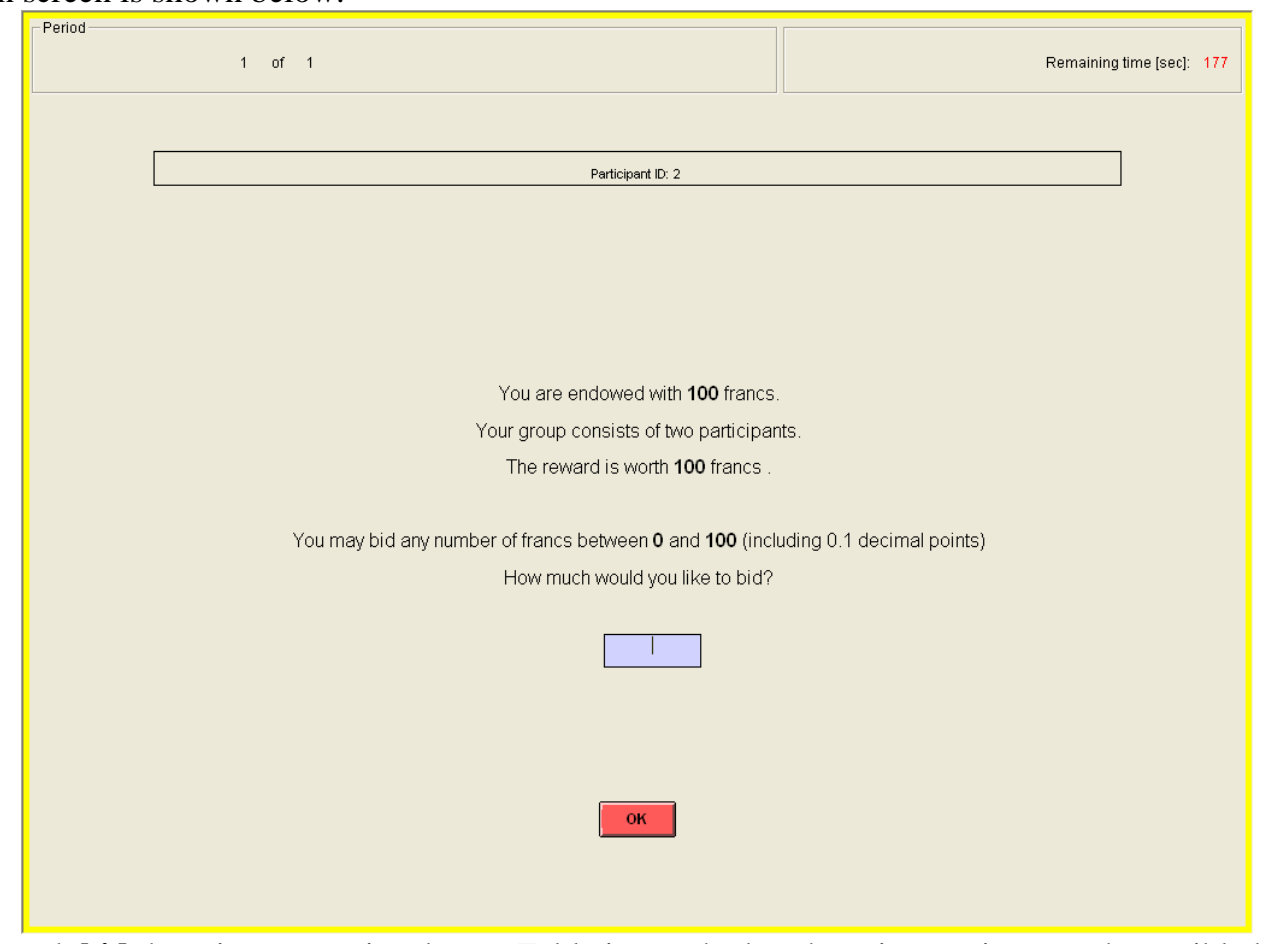

For each bid there is an associated cost. Table is attached to these instructions: each possible bid is given in column A, and its cost is given in column B. Note that as bids rise from 0 to 100 , costs rise exponentially. The cost of bid can be also calculated using the following formula:

Cost of bid $=\frac{(\text { Your bid })^{2}}{100}$

After you make your bid, the computer will multiply it by a "personal random number" to determine your final bid. This number can take any value between 0.5 and 1.5. Each number between 0.5 and 1.5 is equally likely 
to be drawn and there is one separate and independent random draw between 0.5 and 1.5 for each decision period and each person in the lab.

Your final bid $=$ your bid $\times$ your personal random number

\section{YOUR EARNINGS}

After you and the other participant in your group have chosen your bids, the computer will draw the random numbers and compare your final bid to the other participant's final bid, and allocate to you a share of the 100 franc reward according to your share of the sum of the two final bids. In other words, your share is:

$$
\text { Share }=100 \times \quad \text { Your final bid }+ \text { The other participant's final bid }
$$

You also retain any endowment not spent on the bid, so your total earnings for the period are equal to your endowment plus the share minus the cost of your bid. In other words, your earnings are:

$$
\text { Earnings }=\text { Endowment }+ \text { Share }- \text { Cost of your bid }=100+\text { Share }- \text { Cost of your bid }
$$

Note that the cost of your bid is determined by the bid you chose. The random number influences only your share of the final bids for that period.

\section{An Example}

Let's say you make a bid of 36 francs, while the other participant in your group makes a bid of 40 francs, and then your personal random number turns out to be 1.25 while the other participant in your group has a personal random number of 0.8 . Therefore, your final bid is $45=36 \times 1.25$ and the other participant's final bid is $32=40 \times$ 0.8. Your share of the reward is $58.44=100 \times \frac{45}{45+32}$. Finally, your earnings for the period are $145.48=100+58.44$ - 12.96, because the cost of your bid of 36 is 12.96 as shown on your Cost of Bid table.

At the end of each period, your bid, your random number, your final bid, the other participant's bid, the other participant's random number, the other participant's final bid, your share, and your earnings for the period are reported on the outcome screen as shown below. Once the outcome screen is displayed you should record your results for the period on your Personal Record Sheet under the appropriate heading.

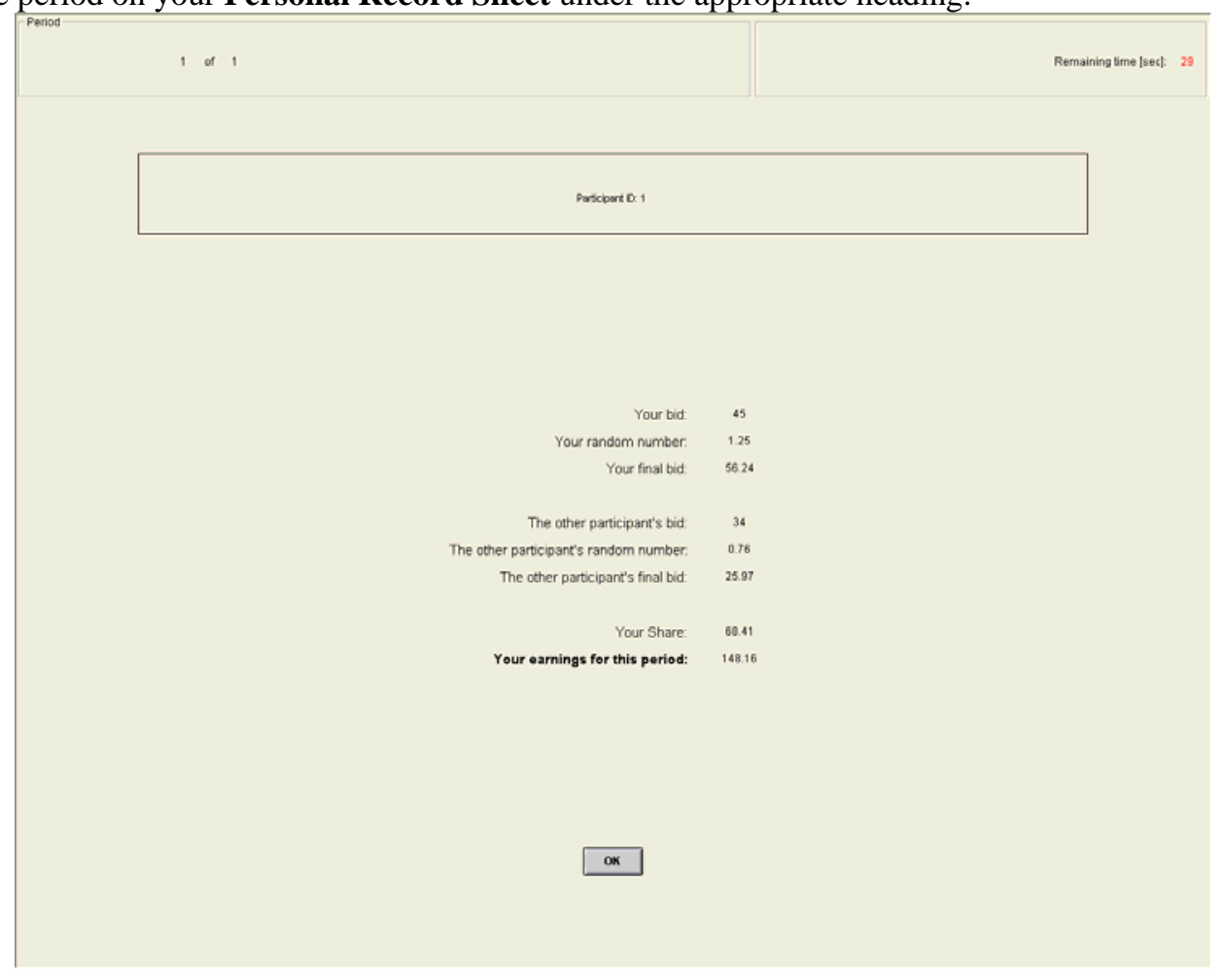




\section{IMPORTANT NOTES}

You will not be told which of the participants in this room are assigned to which group. At the beginning of each period you will be randomly re-grouped with one of the other participants to from a two-person group.

At the end of the experiment we will randomly choose $\mathbf{2}$ of the $\mathbf{2 0}$ periods for actual payment for this part of experiment using a bingo cage. You will sum the total earnings for these 2 periods and convert them to a U.S. dollar payment.

Table - Cost of Bid

\begin{tabular}{|c|c|c|c|c|c|}
\hline \multicolumn{2}{|c|}{ Column A Column B } & \multicolumn{2}{|c|}{ Column A Column B } & \multicolumn{2}{|c|}{ Column A Column B } \\
\hline Bid & Cost of Bid & Bid & Cost of Bid & Bid & Cost of Bid \\
\hline 0 & 0.00 & 34 & 11.56 & 68 & 46.24 \\
\hline 1 & 0.01 & 35 & 12.25 & 69 & 47.61 \\
\hline 2 & 0.04 & 36 & 12.96 & 70 & 49.00 \\
\hline 3 & 0.09 & 37 & 13.69 & 71 & 50.41 \\
\hline 4 & 0.16 & 38 & 14.44 & 72 & 51.84 \\
\hline 5 & 0.25 & 39 & 15.21 & 73 & 53.29 \\
\hline 6 & 0.36 & 40 & 16.00 & 74 & 54.76 \\
\hline 7 & 0.49 & 41 & 16.81 & 75 & 56.25 \\
\hline 8 & 0.64 & 42 & 17.64 & 76 & 57.76 \\
\hline 9 & 0.81 & 43 & 18.49 & 77 & 59.29 \\
\hline 10 & 1.00 & 44 & 19.36 & 78 & 60.84 \\
\hline 11 & 1.21 & 45 & 20.25 & 79 & 62.41 \\
\hline 12 & 1.44 & 46 & 21.16 & 80 & 64.00 \\
\hline 13 & 1.69 & 47 & 22.09 & 81 & 65.61 \\
\hline 14 & 1.96 & 48 & 23.04 & 82 & 67.24 \\
\hline 15 & 2.25 & 49 & 24.01 & 83 & 68.89 \\
\hline 16 & 2.56 & 50 & 25.00 & 84 & 70.56 \\
\hline 17 & 2.89 & 51 & 26.01 & 85 & 72.25 \\
\hline 18 & 3.24 & 52 & 27.04 & 86 & 73.96 \\
\hline 19 & 3.61 & 53 & 28.09 & 87 & 75.69 \\
\hline 20 & 4.00 & 54 & 29.16 & 88 & 77.44 \\
\hline 21 & 4.41 & 55 & 30.25 & 89 & 79.21 \\
\hline 22 & 4.84 & 56 & 31.36 & 90 & 81.00 \\
\hline 23 & 5.29 & 57 & 32.49 & 91 & 82.81 \\
\hline 24 & 5.76 & 58 & 33.64 & 92 & 84.64 \\
\hline 25 & 6.25 & 59 & 34.81 & 93 & 86.49 \\
\hline 26 & 6.76 & 60 & 36.00 & 94 & 88.36 \\
\hline 27 & 7.29 & 61 & 37.21 & 95 & 90.25 \\
\hline 28 & 7.84 & 62 & 38.44 & 96 & 92.16 \\
\hline 29 & 8.41 & 63 & 39.69 & 97 & 94.09 \\
\hline 30 & 9.00 & 64 & 40.96 & 98 & 96.04 \\
\hline 31 & 9.61 & 65 & 42.25 & 99 & 98.01 \\
\hline 32 & 10.24 & 66 & 43.56 & 100 & 100.00 \\
\hline 33 & 10.89 & 67 & 44.89 & & \\
\hline
\end{tabular}

\section{INSTRUCTIONS FOR PART 2 YOUR DECISION}

This part of the experiment consists of $\mathbf{2 0}$ decision-making periods. At the beginning of each period, you will be randomly and anonymously paired with someone else in a group of two participants. The composition of your group will be changed randomly every period. Each period, both participants will be given an initial endowment of 100 francs. You will use this endowment to bid for an additional 100 francs reward available in each period. You may bid any number between $\mathbf{0}$ and $\mathbf{1 0 0}$ (including 0.1 decimal points). An example of your decision screen is shown below. 


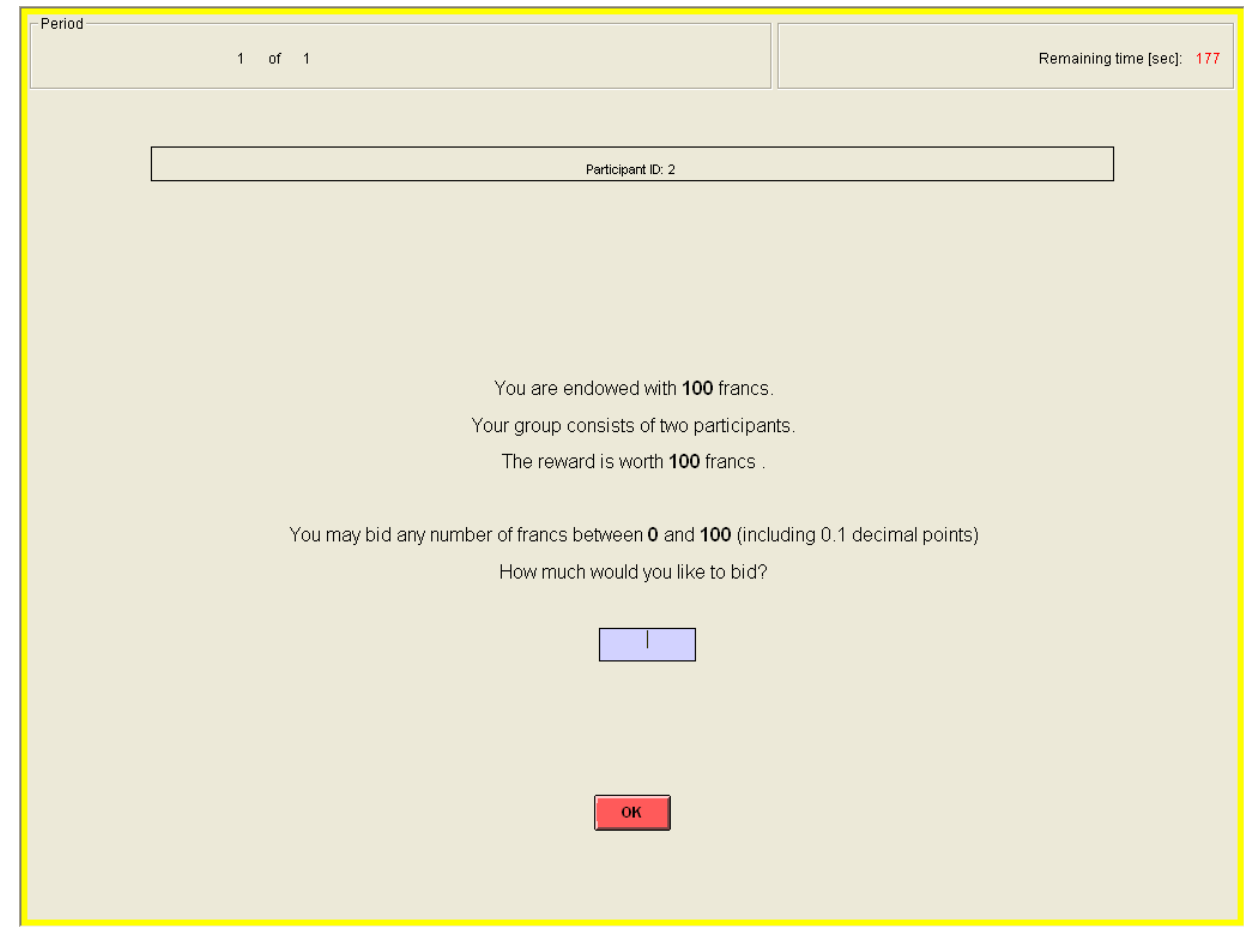

For each bid there is an associated cost. Table is attached to these instructions: each possible bid is given in column A, and its cost is given in column B. Note that as bids rise from 0 to 100 , costs rise exponentially. The cost of bid can be also calculated using the following formula:

$$
\text { Cost of bid }=\frac{(\text { Your bid })^{2}}{100}
$$

After you make your bid, the computer will multiply it by a "personal random number" to determine your final bid. This number can take any value between 0.5 and 1.5. Each number between 0.5 and 1.5 is equally likely to be drawn and there is one separate and independent random draw between 0.5 and 1.5 for each decision period and each person in the lab.

$$
\text { Your final bid }=\text { your bid } \times \text { your personal random number }
$$

\section{YOUR EARNINGS}

After you and the other participant in your group have chosen your bids, the computer will draw the random numbers and compare your final bid to the other participant's final bid. If your final bid is higher than the other participant's final bid, you will receive a reward of $\mathbf{1 0 0}$ francs. Otherwise you will receive $\mathbf{0}$ francs.

If you receive the reward, your earnings for the period are equal to your endowment plus the reward minus the cost of your bid. If you do not receive the reward, your earnings for the period are equal to your endowment minus the cost of your bid. In other words, your earnings are:

\footnotetext{
If you receive the reward:

Earnings $=$ Endowment + Reward - Cost of your bid $=100+100-$ Cost of your bid

If you do not receive the reward:

Earnings $=$ Endowment - Cost of your bid $=100-$ Cost of your bid
}

Note that the cost of your bid is determined by the bid you chose, rather than the final bid influenced by the random number.

\section{An Example}

Let’s say you make a bid of 36 francs while the other participant in your group makes a bid of 40 francs, and then your personal random number turns out to be 1.25 while his personal random number is 0.8 . Therefore, your final bid is $45=36 \times 1.25$ and the other participant's final bid is $32=40 \times 0.8$. Since your final bid of 45 is 
higher than the other participant's final bid of 32, you receive the reward. Your earnings for the period are $187.04=$ $100+100-12.96$, because the cost of your bid of 36 is 12.96 as shown on your Cost of Bid table.

At the end of each period, your bid, your random number, your final bid, the other participant's bid, the other participant's random number, the other participant's final bid, your reward, and your earnings for the period are reported on the outcome screen as shown below. Once the outcome screen is displayed you should record your results for the period on your Personal Record Sheet under the appropriate heading.

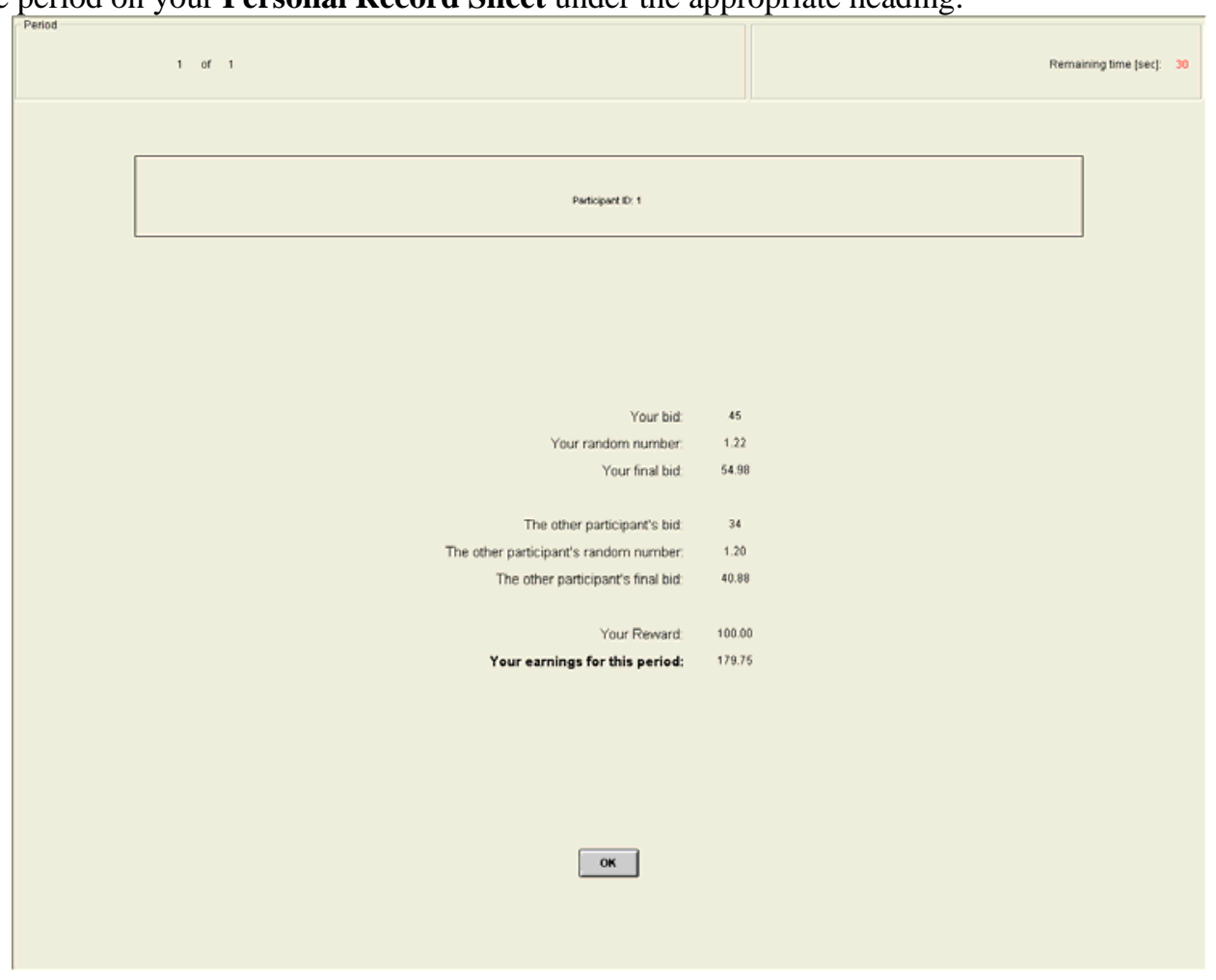

\section{IMPORTANT NOTES}

You will not be told which of the participants in this room are assigned to which group. At the beginning of each period you will be randomly re-grouped with one of the other participants to from a two-person group.

At the end of the experiment we will randomly choose $\mathbf{2}$ of the $\mathbf{2 0}$ periods for actual payment for this part of experiment using a bingo cage. You will sum the total earnings for these 2 periods and convert them to a U.S. dollar payment.

\section{INSTRUCTIONS FOR PART 3}

\section{YOUR DECISION}

This part of the experiment consists of $\mathbf{2 0}$ decision-making periods. At the beginning of each period, you will be randomly and anonymously paired with someone else in a group of two participants. The composition of your group will be changed randomly every period. Each period, both participants will be given an initial endowment of 100 francs. You will use this endowment to bid for an additional 100 francs reward available in each period. You may bid any number between $\mathbf{0}$ and 100 (including 0.1 decimal points). An example of your decision screen is shown below. 


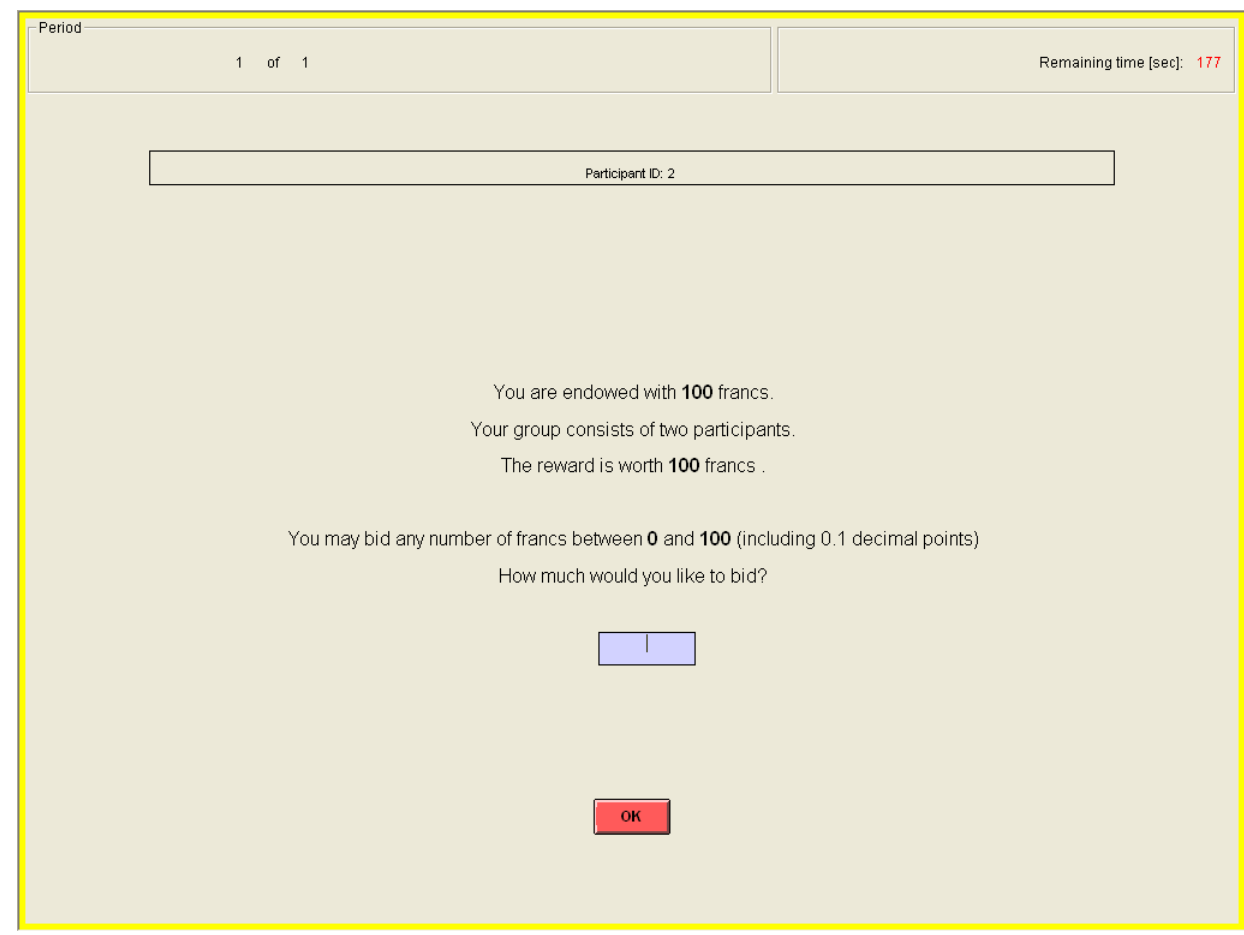

For each bid there is an associated cost. Table is attached to these instructions: each possible bid is given in column A, and its cost is given in column B. Note that as bids rise from 0 to 100 , costs rise exponentially. The cost of bid can be also calculated using the following formula:

Cost of bid $=\frac{(\text { Your bid })^{2}}{100}$

After you make your bid, the computer will multiply it by a "personal random number" to determine your final bid. This number can take any value between 0.5 and 1.5. Each number between 0.5 and 1.5 is equally likely to be drawn and there is one separate and independent random draw between 0.5 and 1.5 for each decision period and each person in the lab.

Your final bid $=$ your bid $\times$ your personal random number

\section{YOUR EARNINGS}

The computer will draw the random numbers to determine your final bid to the other participant's final bid. The chance that you receive the reward is higher when you bid higher, and is lower when the other participant bids higher:

\section{Chance of Receiving the Reward $=$}

Your final bid

Your final bid + The other participant's final bid

You can consider the amounts of the final bids to be equivalent to numbers of lottery tickets. The computer will draw one ticket from those entered by you and the other participant through your final bids, and assign the reward to one of you through this random draw. If you receive the reward, your earnings for the period are equal to your endowment plus the reward minus the cost of your bid. If you do not receive the reward, your earnings for the period are equal to your endowment minus the cost of your bid. In other words, your earnings are:

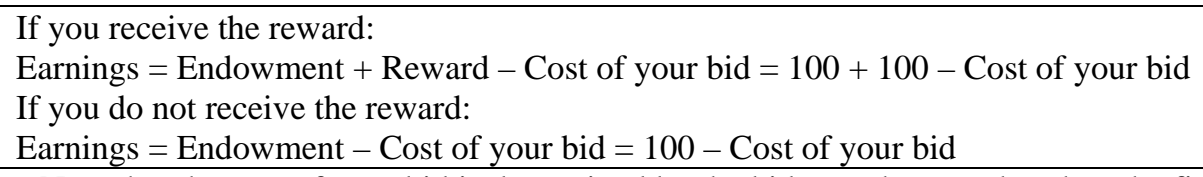

Note that the cost of your bid is determined by the bid you chose, rather than the final bid influenced by the 


\section{An Example}

Let's say you make a bid of 36 francs, while the other participant in your group makes a bid of 40 francs, and then your personal random number turns out to be 1.25 while the other participant in your group has a personal random number of 0.8 . Therefore, your final bid is $45=36 \times 1.25$ and the other participant's final bid is $32=40 \times$ 0.8 . Your chance of receiving the reward is $0.58=45 /(45+32)$. Assume that the computer assigns the reward to you, then your earnings for the period are $187.04=100+100-12.96$, because the cost of your bid of 36 is 12.96 as shown on your Cost of Bid table.

At the end of each period, your bid, your random number, your final bid, the other participant's bid, the other participant's random number, the other participant's final bid, your reward, and your earnings for the period are reported on the outcome screen as shown below. Once the outcome screen is displayed you should record your results for the period on your Personal Record Sheet under the appropriate heading.

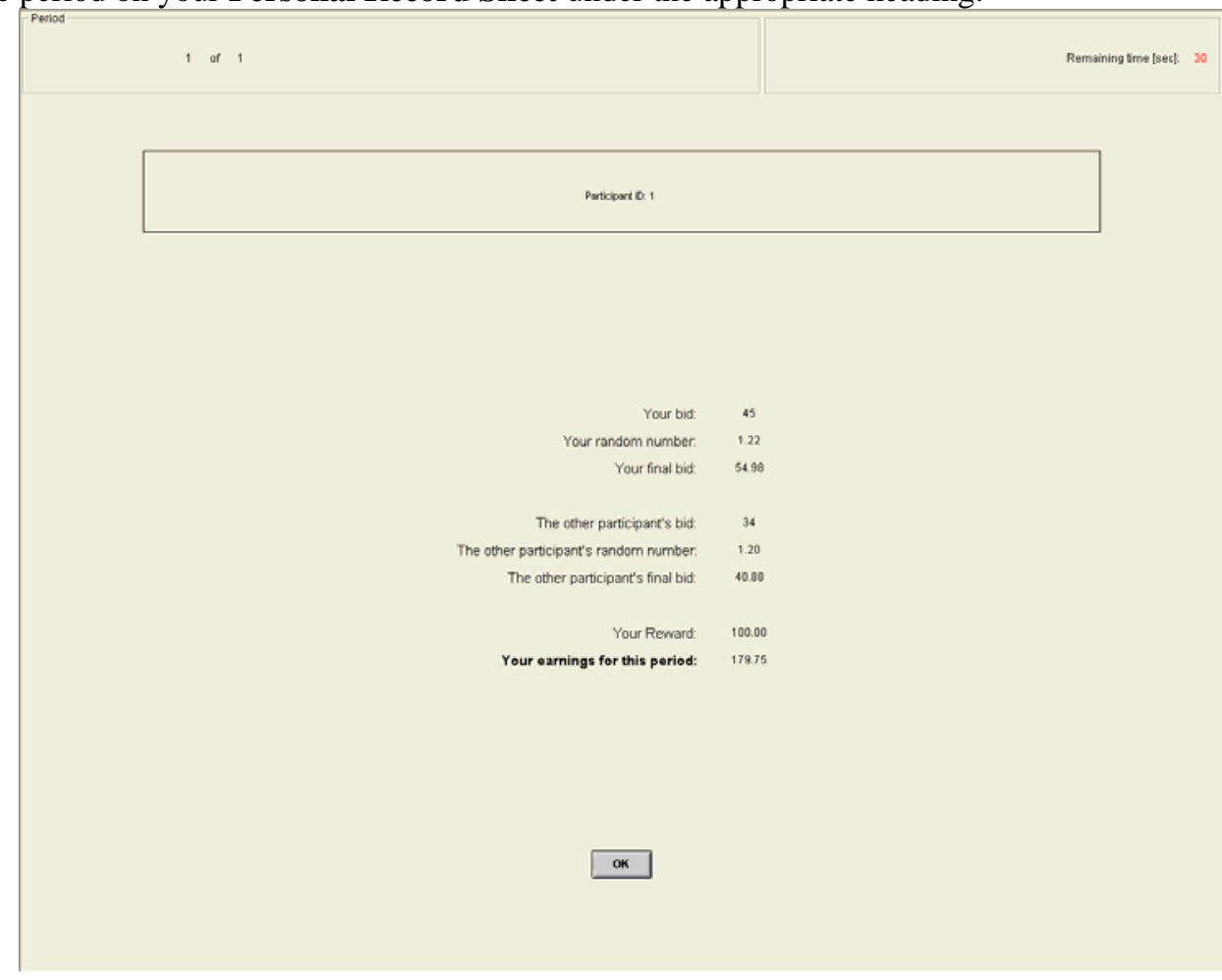

\section{IMPORTANT NOTES}

You will not be told which of the participants in this room are assigned to which group. At the beginning of each period you will be randomly re-grouped with one of the other participants to from a two-person group.

At the end of the experiment we will randomly choose $\mathbf{2}$ of the $\mathbf{2 0}$ periods for actual payment for this part of experiment using a bingo cage. You will sum the total earnings for these 2 periods and convert them to a U.S. dollar payment.

\section{INSTRUCTIONS FOR PART 4}

This part of the experiment consists of only 1 decision-making period. The rules for this part are the same as the rules for Part 2. At the beginning of the period, you will be you randomly and anonymously paired with someone else in a group of two participants. You will be given an initial endowment of $\mathbf{1 0 0}$ francs. You will use this endowment to bid in order to be a winner. You may bid any number between $\mathbf{0}$ and $\mathbf{1 0 0}$ (including 0.1 decimal points). The only difference from Part $\mathbf{2}$ is that the winner does not receive the reward. Therefore, the reward is worth $\mathbf{0}$ francs to you and the other participant in your group.

After you make your bid, the computer will multiply it by a "personal random number" to determine your final bid. This number can take any value between 0.5 and 1.5. Each number between 0.5 and 1.5 is equally likely to be drawn and there is one separate and independent random draw between 0.5 and 1.5 for each decision period and each person in the lab. After you and the other participant in your group have chosen your bids, the computer will draw the random numbers and compare your final bid to the other participant's final bid. If your final bid is 
higher than the other participant's final bid, you will be declared the winner. After all participants have made their decisions, your earnings for the period are calculated:

\section{If you win:}

Earnings $=$ Endowment - Cost of your bid $=100-$ Cost of your bid

If you do not win:

Earnings $=$ Endowment - Cost of your bid $=100-$ Cost of your bid random number.

Note that the cost of your bid is determined by the bid you chose, rather than the final bid influenced by the

After all participants have made their decisions, you will learn whether you win or not. The computer then will display your earnings for the period on the outcome screen. Your earnings will be converted to cash and paid at the end of the experiment.

\section{INSTRUCTIONS FOR PART 5 \\ YOUR DECISION}

In this part of the experiment you will be asked to make a series of choices in decision problems. How much you receive will depend partly on chance and partly on the choices you make. The decision problems are not designed to test you. What we want to know is what choices you would make in them. The only right answer is what you really would choose.

For each line in the table in the next page, please state whether you prefer option A or option B. Notice that there are a total of $\mathbf{1 5}$ lines in the table but just one line will be randomly selected for payment. You do not know which line will be paid when you make your choices. Hence you should pay attention to the choice you make in every line. After you have completed all your choices a token will be randomly drawn out of a bingo cage containing tokens numbered from 1 to 15. The token number determines which line is going to be paid.

Your earnings for the selected line depend on which option you chose: If you chose option A in that line, you will receive $\mathbf{\$ 1}$. If you chose option B in that line, you will receive either $\mathbf{\$ 3}$ or $\mathbf{\$ 0}$. To determine your earnings in the case you chose option B there will be second random draw. A token will be randomly drawn out of the bingo cage now containing twenty tokens numbered from 1 to 20. The token number is then compared with the numbers in the line selected (see the table). If the token number shows up in the left column you earn $\$ 3$. If the token number shows up in the right column you earn $\$ 0$.

\begin{tabular}{|c|c|c|c|c|}
\hline $\begin{array}{l}\text { Deci } \\
\text { sion } \\
\text { no. }\end{array}$ & $\begin{array}{l}\text { Opti } \\
\text { on A }\end{array}$ & & $\begin{array}{c}\text { Option } \\
\text { B }\end{array}$ & $\begin{array}{l}\text { Please } \\
\text { choose } \\
\text { A or B }\end{array}$ \\
\hline 1 & $\$ 1$ & \$3 never & $\$ 0$ if $1,2,3,4,5,6,7,8,9,10,11,12,13,14,15,16,17,18,19,20$ & \\
\hline 2 & $\$ 1$ & $\$ 3$ if 1 comes out of the bingo cage & $\mathbf{\$ 0}$ if $2,3,4,5,6,7,8,9,10,11,12,13,14,15,16,17,18,19,20$ & \\
\hline 3 & \$1 & $\$ 3$ if 1 or 2 & $\$ 0$ if $3,4,5,6,7,8,9,10,11,12,13,14,15,16,17,18,19,20$ & \\
\hline 4 & $\$ 1$ & $\$ 3$ if $1,2,3$ & $\$ \mathbf{0}$ if $4,5,6,7,8,9,10,11,12,13,14,15,16,17,18,19,20$ & \\
\hline 5 & $\$ 1$ & $\$ 3$ if $1,2,3,4$ & $\mathbf{\$ 0}$ if $5,6,7,8,9,10,11,12,13,14,15,16,17,18,19,20$ & \\
\hline 6 & $\$ 1$ & $\$ 3$ if $1,2,3,4,5$ & $\mathbf{\$ 0}$ if $6,7,8,9,10,11,12,13,14,15,16,17,18,19,20$ & \\
\hline 7 & $\$ 1$ & $\$ 3$ if $1,2,3,4,5,6$ & $\$ 0$ if $7,8,9,10,11,12,13,14,15,16,17,18,19,20$ & \\
\hline 8 & $\$ 1$ & $\$ 3$ if $1,2,3,4,5,6,7$ & $\mathbf{\$ 0}$ if $8,9,10,11,12,13,14,15,16,17,18,19,20$ & \\
\hline 9 & $\$ 1$ & $\$ 3$ if $1,2,3,4,5,6,7,8$ & $\$ \mathbf{0}$ if $9,10,11,12,13,14,15,16,17,18,19,20$ & \\
\hline 10 & $\$ 1$ & $\$ 3$ if $1,2,3,4,5,6,7,8,9$ & $\$ 0$ if $10,11,12,13,14,15,16,17,18,19,20$ & \\
\hline 11 & $\$ 1$ & $\$ 3$ if $1,2,3,4,5,6,7,8,9,10$ & $\$ 0$ if $11,12,13,14,15,16,17,18,19,20$ & \\
\hline 12 & $\$ 1$ & $\$ 3$ if $1,2,3,4,5,6,7,8,9,10,11$ & $\$ 0$ if $12,13,14,15,16,17,18,19,20$ & \\
\hline 13 & $\$ 1$ & $\$ 3$ if $1,2,3,4,5,6,7,8,9,10,11,12$ & $\$ 0$ if $13,14,15,16,17,18,19,20$ & \\
\hline 14 & $\$ 1$ & $\$ 3$ if $1,2,3,4,5,6,7,8,9,10,11,12,13$ & $\$ 0$ if $14,15,16,17,18,19,20$ & \\
\hline 15 & $\$ 1$ & $\$ 3$ if $1,2,3,4,5,6,7,8,9,10,11,12,13,14$ & $\$ 0$ if $15,16,17,18,19,20$ & \\
\hline
\end{tabular}

\section{INSTRUCTIONS FOR PART 6 YOUR DECISION}

In this part of the experiment you will be asked to make a series of choices in decision problems. For each line in the table in the next page, please state whether you prefer option A or option B. Notice that there are a total of 4 lines in the table but just one line will be randomly selected for payment. Each line is equally likely to be chosen, so you should pay equal attention to the choice you make in every line. After you have completed all your choices a token will be randomly drawn out of a bingo cage containing tokens numbered from 1 to 4 . The token number determines which line is going to be paid. 
Your earnings for the selected line depend on which option you chose: if you chose option A in that line, you will receive $\mathbf{\$ 2}$ and the other participant who will be matched with you will also receive $\mathbf{2}$. If you chose option $\mathrm{B}$ in that line, you and the other participant will receive earnings as indicated in the table for that specific line. For example, if you chose B in line 2 and this line is selected for payment, you will receive $\$ 3$ and the other participant will receive \$1. Similarly, if you chose B in line 3 and this line is selected for payment, you will receive \$2 and the other participant will receive $\$ \mathbf{4}$.

After you have completed all your choices we will use a bingo cage to determine which line is going to be paid. Then the computer will randomly and anonymously match you with another participant in the experiment. While matching you with another participant, the computer will also randomly determine whose decision to implement. If the computer chooses your decision to implement, then the earnings to you and the other participant will be determined according to your choice of $\mathrm{A}$ or $\mathrm{B}$. If the computer chooses the other participant decision to implement, then the earnings will determined according to the other participant choice of A or B.

\begin{tabular}{|c||c||c||c|}
\hline $\begin{array}{l}\text { Decis } \\
\text { ion } \\
\text { no. }\end{array}$ & $\begin{array}{c}\text { Distribution A } \\
\text { (you, the other participant) }\end{array}$ & $\begin{array}{c}\text { Distribution B } \\
\text { (you, the other participant) }\end{array}$ & $\begin{array}{c}\text { Please } \\
\text { choose } \\
\text { A or B }\end{array}$ \\
\hline 1 & \$2 to you, \$2 to other participant & \$2 to you, \$1 to other participant & \\
\hline 2 & \$2 to you, \$2 to other participant & \$3 to you, \$1 to other participant & \\
\hline 3 & \$2 to you, \$2 to other participant & \$2 to you, \$4 to other participant & \\
\hline 4 & \$2 to you, \$2 to other participant & \$3 to you, \$5 to other participant & \\
\hline
\end{tabular}


2012

\section{Economic Science Institute Working Papers}

12-01 Kimbrough, E. and Sheremeta, R. Side-Payments and the Costs of Conflict. 2011

11-19 Cason, T., Savikhin, A. and Sheremeta, R. Behavioral Spillovers in Coordination Games.

11-18 Munro, D. and Rassenti, S. Combinatorial Clock Auctions: Price Direction and Performance.

11-17 Schniter, E., Sheremeta, R., and Sznycer, D. Restoring Damaged Trust with Promises, Atonement and Apology.

11-16 Brañas-Garza, P., and Proestakis, A. Self-discrimination: A field experiment on obesity.

11-15 Brañas-Garza, P., Bucheli, M., Paz Espinosa, M., García-Muñoz, T. Moral cleansing and moral licenses: experimental evidence.

11-14 Caginalp, G., Porter, D., and Hao, L. Asset Market Reactions to News: An Experimental Study.

11-13 Porter, D., Rassenti, S. and Smith, V. The Effect of Bidding Information in Ascending Auctions.

11-12 Schniter, E., Sheremeta, R. and Shields, T. Conflicted Minds: Recalibrational Emotions Following Trust-based Interaction.

11-11 Pedro Rey-Biel, P., Sheremeta, R. and Uler, N. (Bad) Luck or (Lack of) Effort?: Comparing Social Sharing Norms between US and Europe.

11-10 Deck, C., Porter, D., Smith, V. Double Bubbles in Assets Markets with Multiple Generations.

11-09 Kimbrough, E., Sheremeta, R., and Shields, T. Resolving Conflicts by a Random Device.

11-08 Brañas-Garza, P., García-Muñoz, T., and Hernan, R. Cognitive effort in the Beauty Contest Game.

11-07 Grether, D., Porter, D., and Shum, M. Intimidation or Impatience? Jump Bidding in On-line Ascending Automobile Auctions.

11-06 Rietz, T., Schniter, E., Sheremeta, R., and Shields, T. Trust, Reciprocity and Rules.

11-05 Corgnet, B., Hernan-Gonzalez, R., and Rassenti, S. Real Effort, Real Leisure and Real-time Supervision: Incentives and Peer Pressure in Virtual Organizations. 
11-04 Corgnet, B. and Hernán-González R. Don’t Ask Me If You Will Not Listen: The Dilemma of Participative Decision Making.

11-03 Rietz, T., Sheremeta, R., Shields, T., Smith, V. Transparency, Efficiency and the Distribution of Economic Welfare in Pass-Through Investment Trust Games.

11-02 Corgnet, B., Kujal, P. and Porter, D. The Effect of Reliability, Content and Timing of Public Announcements on Asset Trading Behavior.

11-01 Corgnet, B., Kujal, P. and Porter, D. Reaction to Public Information in Markets: How Much Does Ambiguity Matter?

\section{0}

10-23 Sheremeta, R. Perfect-Substitutes, Best-Shot, and Weakest-Link Contests between Groups. 10-22 Mago, S., Sheremeta, R., and Yates, A. Best-of-Three Contests: Experimental Evidence. 10-21 Kimbrough, E. and Sheremeta, R. Make Him an Offer He Can't Refuse: Avoiding Conflicts Through Side Payments.

10-20 Savikhim, A. and Sheremeta, R. Visibility of Contributions and Cost of Inflation: An Experiment on Public Goods.

10-19 Sheremeta, R. and Shields, T. Do Investors Trust or Simply Gamble?

10-18 Deck, C. and Sheremeta, R. Fight or Flight? Defending Against Sequential Attacks in the Game of Siege.

10-17 Deck, C., Lin, S. and Porter, D. Affecting Policy by Manipulating Prediction Markets: Experimental Evidence.

10-16 Deck, C. and Kimbrough, E. Can Markets Save Lives? An Experimental Investigation of a Market for Organ Donations.

10-15 Deck, C., Lee, J. and Reyes, J. Personality and the Consistency of Risk Taking Behavior: Experimental Evidence.

10-14 Deck, C. and Nikiforakis, N. Perfect and Imperfect Real-Time Monitoring in a Minimum-Effort 
Game.

10-13 Deck, C. and Gu, J. Price Increasing Competition? Experimental Evidence.

10-12 Kovenock, D., Roberson, B.,and Sheremeta, R. The Attack and Defense of Weakest-Link Networks.

10-11 Wilson, B., Jaworski, T., Schurter, K. and Smyth, A. An Experimental Economic History of Whalers’ Rules of Capture.

10-10 DeScioli, P. and Wilson, B. Mine and Thine: The Territorial Foundations of Human Property. 10-09 Cason, T., Masters, W. and Sheremeta, R. Entry into Winner-Take-All and Proportional-Prize Contests: An Experimental Study.

10-08 Savikhin, A. and Sheremeta, R. Simultaneous Decision-Making in Competitive and Cooperative Environments.

10-07 Chowdhury, S. and Sheremeta, R. A generalized Tullock contest.

10-06 Chowdhury, S. and Sheremeta, R. The Equivalence of Contests.

10-05 Shields, T. Do Analysts Tell the Truth? Do Shareholders Listen? An Experimental Study of Analysts' Forecasts and Shareholder Reaction.

10-04 Lin, S. and Rassenti, S. Are Under- and Over-reaction the Same Matter? A Price Inertia based Account.

10-03 Lin, S. Gradual Information Diffusion and Asset Price Momentum.

10-02 Gjerstad, S. and Smith, V. Household expenditure cycles and economic cycles, 1920 - 2010.

10-01 Dickhaut, J., Lin, S., Porter, D. and Smith, V. Durability, Re-trading and Market Performance. 2009

09-11 Hazlett, T., Porter, D., Smith, V. Radio Spectrum and the Disruptive Clarity OF Ronald Coase.

09-10 Sheremeta, R. Expenditures and Information Disclosure in Two-Stage Political Contests.

09-09 Sheremeta, R. and Zhang, J. Can Groups Solve the Problem of Over-Bidding in Contests?

09-08 Sheremeta, R. and Zhang, J. Multi-Level Trust Game with "Insider" Communication. 
09-07 Price, C. and Sheremeta, R. Endowment Effects in Contests.

09-06 Cason, T., Savikhin, A. and Sheremeta, R. Cooperation Spillovers in Coordination Games.

09-05 Sheremeta, R. Contest Design: An Experimental Investigation.

09-04 Sheremeta, R. Experimental Comparison of Multi-Stage and One-Stage Contests.

09-03 Smith, A., Skarbek, D., and Wilson, B. Anarchy, Groups, and Conflict: An Experiment on the Emergence of Protective Associations.

09-02 Jaworski, T. and Wilson, B. Go West Young Man: Self-selection and Endogenous Property Rights.

09-01 Gjerstad, S. Housing Market Price Tier Movements in an Expansion and Collapse.

2008

08-09 Dickhaut, J., Houser, D., Aimone, J., Tila, D. and Johnson, C. High Stakes Behavior with Low Payoffs: Inducing Preferences with Holt-Laury Gambles.

08-08 Stecher, J., Shields, T. and Dickhaut, J. Generating Ambiguity in the Laboratory.

08-07 Stecher, J., Lunawat, R., Pronin, K. and Dickhaut, J. Decision Making and Trade without Probabilities.

08-06 Dickhaut, J., Lungu, O., Smith, V., Xin, B. and Rustichini, A. A Neuronal Mechanism of Choice.

08-05 Anctil, R., Dickhaut, J., Johnson, K., and Kanodia, C. Does Information Transparency

Decrease Coordination Failure?

08-04 Tila, D. and Porter, D. Group Prediction in Information Markets With and Without Trading Information and Price Manipulation Incentives.

08-03 Thomas, C. and Wilson, B. Horizontal Product Differentiation in Auctions and Multilateral Negotiations.

08-02 Oprea, R., Wilson, B. and Zillante, A. War of Attrition: Evidence from a Laboratory Experiment on Market Exit.

08-01 Oprea, R., Porter, D., Hibbert, C., Hanson, R. and Tila, D. Can Manipulators Mislead Prediction Market Observers? 